\title{
Stochastic maintenance models for ceramic claddings
}

\section{Cláudia Ferreira, Luís Canhoto Neves, Ana Silva \& Jorge de Brito}

To cite this article: Cláudia Ferreira, Luís Canhoto Neves, Ana Silva \& Jorge de Brito (2020) Stochastic maintenance models for ceramic claddings, Structure and Infrastructure Engineering, 16:2, 247-265, DOI: 10.1080/15732479.2019.1652657

To link to this article: https://doi.org/10.1080/15732479.2019.1652657

册Published online: 16 Aug 2019.

Submit your article to this journal $\sqsubset$

山ll Article views: 163

Q View related articles ๘

View Crossmark data \lceil

Citing articles: 10 View citing articles 진 


\title{
Stochastic maintenance models for ceramic claddings
}

\author{
Cláudia Ferreira ${ }^{a}$, Luís Canhoto Neves ${ }^{b}$ (D) Ana Silva $^{c}$ (D) and Jorge de Brito ${ }^{c}$ (D) \\ ${ }^{a}$ FCT-UNL, Faculty of Sciences and Technology, New University of Lisbon, Caparica, Portugal; ${ }^{b}$ Resilience Engineering Research Group, \\ University of Nottingham, Nottingham, UK; ${ }^{C}$ CERIS, Department of Civil Engineering, Architecture and Georesources, Instituto Superior \\ Técnico, University of Lisbon, Av. Rovisco Pais, Lisboa, Portugal
}

\begin{abstract}
Maintenance decision-making involves a series of multiple objectives, some of them contradictory. Usually, stakeholders intend to find the optimal maintenance strategy, to minimize the economic burden, while simultaneously maximizing the buildings' performance. In this study, a condition-based maintenance model, based on Petri nets, is proposed to evaluate the consequences of alternative maintenance strategies to maintain and improve the performance of ceramic claddings. This maintenance model is a full life-cycle model that integrates the stochastic assessment of the degradation condition of the claddings, and also inspections, maintenance and renewal processes. Three maintenance strategies are considered: (i) major intervention only; (ii) combination of minor and major interventions; and (iii) combination of cleaning operations, minor and major interventions. The uncertainties associated with the degradation process, as well as with the definition of the effects of maintenance actions are considered by modelling the transitions times in Petri nets as random variables. Considering the complexity of Petri nets, the statistical descriptors of the performance of the assets (e.g., mean condition, probability of applying maintenance) were computed using Monte Carlo simulation. The impact of the different maintenance strategies in the claddings' service life is discussed, comparing the different alternatives also from an economic point of view.
\end{abstract}

\section{ARTICLE HISTORY}

Received 16 November 2018 Revised 30 May 2019

Accepted 30 July 2019

\section{KEYWORDS}

Ceramic claddings; degradation; inspections; interventions; maintenance modeling; Petri nets; Monte Carlo simulation

\section{Introduction}

In the last decades, concern related with effective maintenance of constructed facilities has increased. This trend is mainly due to: i) the growing complexity of buildings; ii) a greater awareness of the influence of maintenance activities on the buildings' life-cycle costs, which is strengthened in the light of the limited budget commonly allocated for these activities; iii) a substantial increase in the users' performance requirements; and iv) the acknowledge that the building's performance is highly dependent on its maintenance (Shohet, 2006).

Recently, a significant effort has been invested on the development of decision-aiding tools for maintenance planning of buildings. These tools provide quantitative means to predict the service life of building components at different levels of performance, and to evaluate the impact of maintenance strategies adopted by owners of large facilities stocks (Shohet, Puterman, \& Gilboa, 2002). The users' perceptions and requirements, as well as the available budget for maintenance actions, strongly influence the implementation of maintenance policies (Flores-Colen \& de Brito, 2010; Lowry, 2002). For instance, hotels and hospitals demand that most of the building components and systems perform at the highest level. On the other hand, owners of residential buildings may be satisfied with keeping their facility at an 'acceptable' level of service, in order to minimize the maintenance costs. These different demands call for a flexible tool that will make possible an effective evaluation of the service life of building components based on their actual condition, according to different desired performance levels (Shohet et al., 2002).

In this sense, stakeholders urgently need flexible and accurate tools for cost-effectively allocate limited budgets for the maintenance of aging and degraded buildings and components, in order to optimize not only the buildings' performance but also the whole-life maintenance costs (Frangopol \& Liu, 2007). These tools should be based on the diagnosis of in-service performance, thus recommending different actions according to a given condition state during the buildings' service life (Flores-Colen, de Brito, \& Freitas, 2009). Sherwin (2000) refers that, whereas the mathematical models for maintenance management are not able to ensure optimality, without them the decisions related with the adoption of maintenance activities would almost certainly be worse. These mathematical models should encompass the uncertainty related with the degradation mechanisms under no maintenance and under different maintenance activities (Frangopol \& Liu, 2007).

The main objective of this work is the development and implementation of a life-cycle model for ceramic claddings, considering preventive and reactive maintenance actions. The proposed model will be implemented using a stochastic Petri net framework. The case study selected was composed of 195 ceramic claddings, located in Lisbon, Portugal, as 
Table 1. Literature review of research works that apply Petri nets to the assessment of the deterioration and maintenance processes.

\begin{tabular}{|c|c|}
\hline Reference & Application/objectives/domain \\
\hline Yang and Liu (1998) & $\begin{array}{l}\text { Hybrid Petri net arrangement is proposed to analyse early failure detection and isolation of heating and } \\
\text { cooling systems. }\end{array}$ \\
\hline Simeu-Abazi and Sassine (1999) & $\begin{array}{l}\text { A modular modelling approach, based on a cellular decomposition of the system using stochastic Petri nets and } \\
\text { Markov chains, is adopted to evaluate various maintenance strategies in manufacturing systems. }\end{array}$ \\
\hline Lei et al. (2010) & $\begin{array}{l}\text { A modularized simulation package for manufacturing production system is developed using standard stochastic } \\
\text { timed Petri nets. A maintenance decision support tool is developed to provide offline and online maintenance } \\
\text { decision support for production lines. }\end{array}$ \\
\hline Zille et al. (2011) & $\begin{array}{l}\text { A modelling approach based on Petri nets is presented to assess the performance of multicomponent systems } \\
\text { maintained by complex maintenance strategies. A global framework is built to describe the evolution of the } \\
\text { system, the way its components can degrade and fail, and the effects of different maintenance actions. }\end{array}$ \\
\hline Andrews (2013) & $\begin{array}{l}\text { A Petri net formulation using Monte Carlo simulation is used to evaluate the impact of different maintenance } \\
\text { strategies on railway track geometry and condition of the ballast. }\end{array}$ \\
\hline Le and Andrews (2016a) & $\begin{array}{l}\text { Petri nets are used to model the deterioration of individual components of bridges. The bridge model is formed } \\
\text { from sub-models of each of its components and takes into consideration the component deterioration process, } \\
\text { the interaction and dependency between different component deterioration processes, along with the inspection } \\
\text { and maintenance processes. }\end{array}$ \\
\hline Le and Andrews (2016b) & $\begin{array}{l}\text { Petri nets are used to develop a lifecycle asset model for offshore wind turbine reliability accounting for the } \\
\text { degradation, inspection and maintenance processes, to predict their future condition and investigate the effect } \\
\text { of a maintenance strategy. }\end{array}$ \\
\hline Leigh and Dunnett (2016) & $\begin{array}{l}\text { Petri nets are used to simulate the effect of weather conditions and periodic, conditional and corrective } \\
\text { maintenance actions on the performance wind turbines. }\end{array}$ \\
\hline Eisenberger and Fink (2017) & $\begin{array}{l}\text { Abridged Petri nets are used to model the maintenance strategy of railway rolling stock components and } \\
\text { demonstrate how their specific requirements and boundary conditions can be implemented to enable a suitable } \\
\text { and easy to use decision support tool. }\end{array}$ \\
\hline Yianni et al. (2017) & $\begin{array}{l}\text { Petri nets are employed to model lifecycle performance of bridge components by combining deterioration, } \\
\text { inspection and maintenance models. The resulting model consists in different modules each with its own source } \\
\text { of data, calibration methodology and functionality. }\end{array}$ \\
\hline Zhang et al. (2017) & Petri nets are used to model rail degradation and maintenance and, thus, identify optimal maintenance strategies. \\
\hline $\begin{array}{l}\text { Ferreira, Neves, Silva, \& } \\
\quad \text { de Brito (2018) }\end{array}$ & $\begin{array}{l}\text { Stochastic Petri nets are used to model and predict the life-cycle performance of building façades. The model } \\
\text { evaluates the performance of rendered façades over time, evaluating the uncertainty of the future performance } \\
\text { of these coatings. }\end{array}$ \\
\hline Kilsby et al. (2019) & $\begin{array}{l}\text { Proposes a probabilistic asset management and life cycle cost analysis framework for railway overhead line } \\
\text { equipment using a stochastically timed high-level Petri nets. The method is based on a whole-system model, } \\
\text { where the relationships between the individual components of the system are considered in terms of their } \\
\text { degradation, failure, inspection and maintenance processes. }\end{array}$ \\
\hline Ferreira et al. (2019) & $\begin{array}{l}\text { A stochastic Petri net formalism is proposed to predict the degradation of ceramic claddings over time in order to } \\
\text { understand how different environmental exposure conditions contribute to the overall degradation of } \\
\text { these claddings. }\end{array}$ \\
\hline
\end{tabular}

detailed data on the deterioration of these elements were available. The sample was established based on the diagnosis of the degradation condition of these claddings in-service performance, through in situ visual inspections. The model developed is, nevertheless, very general and can be applied to a range of building components, including natural stone claddings, wall renderings, painted walls, among others.

Petri nets have been successfully applied to model dynamic systems in several areas due to their flexibility and high accuracy in modelling complex phenomena, including robotics (Al-Ahmari, 2016), optimization of manufacturing systems (Chen, Li, \& Barkaoui, 2014; Uzam, Gelen, \& Saleh, 2016), business process management (van der Aalst, 2002), and human computer interaction (Tang, Guo, Dong, Li, \& Guan, 2008). Table 1 summarizes various research works using Petri nets to model maintenance and life-cycle approaches. The application of Petri nets to the assessment of the deterioration and maintenance processes in the civil engineering infrastructures is a recent research field as most previous works focus on industrial systems and/or mechanical components. In relation to building asset modelling, the implementation of Petri nets to model deterioration and maintenance is a very recent and innovative area. Nevertheless, there are several works (Cheng, Li, Wang, Skitmore, \& Forsythe, 2013; Li, 1998; Molinero \& Nunez, 2011; Rinke et al., 2017) that use Petri nets to manage resources, to estimate equipment availability and scheduling of tasks on the site-work during the building design process. Petri nets can be seen as a generalization of Markov chains, overcoming some of the latter's limitations by: i) allowing the transition time between states to be modelled using distributions other than the exponential distribution; ii) providing a graphical depiction of all processes considered in the life-cycle model, allowing a better communication of the principles, limitations and results to all stakeholders; and iii) allowing the development of significantly more complex models, which can comprise a range of features including modelling of inspections, maintenance and deteriorations.

The maintenance model described can be considered a full life-cycle model that includes not only the deterioration process but also the inspections, maintenance and renewal options. The transition times between different deterioration levels and the inspection times are sampled from appropriate probability distributions that are defined based on the literature and experts' opinion. In this study, the uncertainties associated with the degradation process are treated in Petri net model using Monte Carlo simulation.

The proposed model allows predicting: i) future condition profiles, considering different maintenance strategies; ii) the number of interventions performed in the ceramic claddings over the simulated lifetime; iii) intervention timings; 


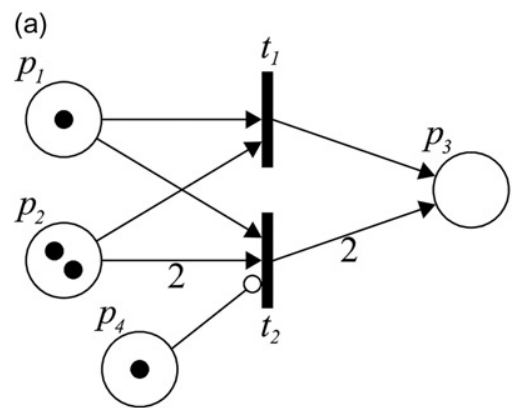

(b)

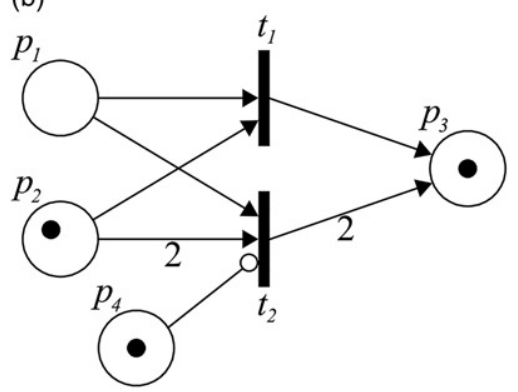

Figure 1. Example of a Petri net: (a) before; and (b) after firing of the transition.

and, iv) the cumulative cost profile of the different maintenance strategies, considering the annual discount rate.

In the methodology used to evaluate the performance of ceramic claddings, three maintenance strategies are considered: (i) major intervention only, which considers the claddings' replacement; (ii) combination of minor and major interventions; and (iii) combination of cleaning operations, minor and major interventions. The first maintenance strategy represents the most common solution adopted by the buildings' owners. The other two strategies are analysed in order to evaluate the impact of the different alternatives in the claddings' service life and in the whole-life maintenance costs, for the period under analysis. The results show that the model is a useful tool to aid the maintenance decisionmaking process by allowing the identification of the most appropriate strategy, considering the claddings' performance and the overall maintenance costs.

\section{Petri nets}

The original concept of Petri nets was introduced by Carl A. Petri (Petri, 1962). A Petri net is defined as a bipartite weighted directed graph with an initial state called initial marking, $M_{0}$ (Murata, 1989; Peterson, 1977; Schneeweiss, 2004). Pictorially, it is composed by four main elements: places; transitions; arcs; and tokens.

Places and transitions are nodes of the network. Places represent a specific state or condition of the system whereas transitions are used to represent the triggering of events or actions. Connections between nodes are made by weighted directed arcs. An arc can only connect a place with a transition or vice-versa and is labelled with a weight (positive integer number), where a $k$-weighted arc can be understood as a set of $k$ parallel arcs (for simplicity's sake, when the arc weight is equal to 1 , the label of the arc is usually omitted).
Tokens are stored in places and the distribution of the tokens on the places represents the current state of the system, and are called the marking of the network, $M$.

The Petri net methodology described in this study is an extension of the original concept. The extensions correspond to properties that have been added, in order to enhance the original concept of $\mathrm{PN}$, thereby enabling a greater number of applications to be treated (David \& Alla, 2010), allowing making the methodology more concise and efficient (Le \& Andrews, 2016a). All extensions implemented in this work are discussed below.

Figure 1 illustrates a simple Petri net. The net is composed of four places and two transitions. Both transitions have two input places $\left(p_{1}, p_{2}\right)$ and one output place $\left(p_{3}\right)$. The arcs that connect the input places to the transition and the transition to the output places represent the pre- and post-conditions of the transition, respectively. The arc connecting place $p_{4}$ to transition $t_{2}$ is denoted by an inhibitor arc and allows prioritizing the firing of transitions (Baskocagil \& Kurtulan, 2011; Peterson, 1977). This arc indicates that place $p_{4}$ is an inhibitor place and, when marked, transition $t_{2}$ is forbidden from firing.

Transitions together with the tokens are responsible for the evolving of the system, from one state to another. The dynamic behaviour of the system is modelled through the transition (firing) rule (Murata, 1989). For the firing process to happen, transition must be enabled. This requires that each input place is marked with at least a number of tokens equal to the arc weight. In the example presented in Figure 1(a), both transitions are enabled. However, the presence of a token in place $p_{4}$ inhibits the firing of transition $t_{2}$. After transition $t_{1}$ 's firing, Figure 1(b), the marking of the net has changed, and none of the transitions is therewith enabled. The inhibitor arc solves the potential conflict between transitions $t_{1}$ and $t_{2}$. As shown in Figure $1(\mathrm{a})$, when both places $p_{1}$ and $p_{2}$ are occupied, both transitions can be fired. The marking of place $p_{4}$, inhibits the transition $t_{2}$, and thus gives priority to transition $t_{1}$.

In the original concept of Petri nets, transitions are associated with a firing rate equal to zero, i.e. immediate transitions (Marsan, Conte, \& Balbo, 1984; Murata, 1989). However, to produce a more resourceful model, new types of transitions were added to improve the methodology and to accommodate the modelling needs. In deterministic transitions, a constant time delay associated with the transition is established. This type of transitions allows modelling discrete processes and changing the qualitative behaviour of the model with respect to the untimed Petri nets (Marsan \& Chiola, 1986). In stochastic Petri nets, transitions are defined to be random variables with given statistical distributions. This type of transitions is very useful to model random processes, and the firing rate can be defined from different probabilistic distributions (Dugan, Trivedi, Geist, \& Nicola, 1984, Marsan \& Chiola, 1986).

The reset transition has associated a list of places and number of tokens that each place will contain after the Petri net is reset. In other words, the reset transition allows defining a new marking for the network when fired, and thereby simplifying the model. A reset action can be performed 
using the original concept of PN but would require a large number of transitions and places to be added to the model, which would increase its size and complexity, confusing the engineering process that is being modelled (Andrews, 2013; Le \& Andrews, 2016a).

\section{Deterioration of ceramic claddings}

Ceramic claddings are considered by users a durable material, with interesting aesthetic characteristics and relatively resilient to aggressive environments (CEN, 2012; Plšková, Chobola, \& Matysik, 2011). However, the maintenance of ceramic claddings is often neglected (Thai-Ker \& Chung-Wan, 2006). The adoption of null or inadequate maintenance practices, in association with the natural degradation of ceramic claddings (due to the exposure to all types of environmental conditions), as well as faulty design and execution errors, naturally leads to the deterioration of these claddings. In some cases, their deterioration is premature, presenting visible defects in the first two years after construction (Shohet et al., 2002). These defects can be easily revealed, measured and controlled through regular inspections and an adequate maintenance program. But regular inspections on buildings are not mandatory and the performance levels of the different building components are usually defined by the owners (Thai-Ker \& Chung-Wan, 2006).

An accurate modelling of the degradation condition of ceramic claddings is an important step for the definition of maintenance management models. Over the last decade, several studies have addressed the inspection and characterization of the degradation condition of ceramic claddings (Bordalo, de Brito, Gaspar, \& Silva, 2011; Silva, Gaspar, de Brito, \& Neves, 2016; Silvestre \& de Brito, 2011). In this study, a quantitative scale is adopted for the evaluation of the physical and visual condition of the sample analysed, according to previous studies of ours (Ferreira, Neves, Silva, \& de Brito, 2019; Silva, de Brito, \& Gaspar, 2016).

This numerical scale is based on the severity and extent of the defects observed in the ceramic claddings analysed. The defects observed in ceramic claddings are converted into a numerical index, denoted as severity of degradation, $S_{w}$, which is computed as the ratio between the extent of the claddings' degradation, weighted as a function of the degradation level and the severity of the defects, and a reference area, equivalent to the maximum theoretical extent of the degradation for the cladding analysed, as follows:

$$
S_{w}=\frac{\sum\left(A_{n} \times k_{n} \times k_{a, n}\right)}{A \times k}
$$

where $S_{w}$ is the degradation severity of the coating, expressed as a percentage; $k_{n}$ is the multiplying factor of anomaly $n$, as a function of their degradation level, within the range $K=\{0,1,2,3,4\} ; k_{a, n}$ is a weighting factor corresponding to the relative $E_{\text {weight }}$ of the anomaly detected $\left(k_{a, n} \in R+\right) ; k_{a, n}=1$ by default; $A_{n}$ is the area of coating affected by an anomaly $n$; $A$ is the façade area; and $k$ is the multiplying factor corresponding to the highest degradation level of a coating of area $A$.
Table 2 presents the scale adopted, according to the defects observed in ceramic claddings, as well as the weighting coefficients applied in Equation (1). The weighting coefficients $\left(k_{a, n}\right)$ are used to hierarchise the relative importance between anomalies. Naturally, different anomalies present different effects on the overall degradation condition of the ceramic claddings, e.g. the detachment of ceramic tiles is an extremely serious anomaly, jeopardizing the users' safety, while stains only compromise the aesthetic appearance of the cladding. In this sense, the weighting coefficients $\left(k_{a, n}\right)$ are established based on the severity of the anomalies, the impact of the anomalies in the claddings' performance (safety and weathertightness), the propensity to generate new anomalies and the cost of repair (Bordalo et al., 2011; Silva, de Brito, et al., 2016). The weighting coefficients are mainly quantified by the cost of repair of the anomalies, i.e. the $\left(k_{a, n}\right)$ for each anomaly is given by the ration between the cost of repair of that anomaly and the cost of replacing the cladding.

The severity of degradation index is translated, in this study, into five degradation levels, ranging from A (no visual deterioration - most favourable situation) to $\mathrm{E}$ (worst condition level). In the literature, different authors (Balaras, Droutsa, Dascalaki, \& Kontoyiannidis, 2005; Brandt \& Rasmussen, 2002; Flourentzou, Brandt, \& Wetzel, 2000; Kirkham \& Boussabaine, 2005; Shohet \& Paciuk, 2004) have suggested the adoption of degradation scales, to express the physical and visual deterioration of building components. These scales are usually composed of discrete variables, some of them with five levels, describing the loss of performance of the components, from the absence of visible degradation to the most unfavourable condition, related to the loss of functionality of the component under analysis (Bordalo et al., 2011; Gaspar \& de Brito, 2011; Silva, de Brito, et al., 2016).

Figure 2 presents an illustrative example of the visual condition of ceramic claddings in each degradation level. Level A corresponds to a cladding with no visible degradation; the ceramic cladding in Level B starts to present some visual defects (superficial dirt and stains), which do not jeopardize the claddings' performance; Level C corresponds to a ceramic cladding with slight deterioration, with some anomalies related with the degradation of the ceramic tiles surface, e.g. crushing or scaling of the borders; Level D corresponds to a ceramic cladding with some joint defects, with loss of the filling material, as well as other pathological manifestations, related with the degradation of the ceramic tiles' surface; and finally, in Level E, the claddings show a generalised deterioration, with severe loss of adherence defects, associated with other anomalies that are also present in more favourable conditions.

\section{Application of Petri nets to the definition of a maintenance model}

\subsection{Model assumptions}

The proposed life-cycle model is based on current and potential future practice in terms of inspection, maintenance 
Table 2. Description of the degradation conditions for ceramic claddings (data sourced from Silva, de Brito, 2016b).

\begin{tabular}{|c|c|c|c|c|c|}
\hline Degradation levels & Groups of defects & Description & $k_{a, n}$ & $\begin{array}{c}\% \text { area of } \\
\text { cladding affected }\end{array}$ & $\begin{array}{c}\text { Severity of } \\
\text { degradation (\%) }\end{array}$ \\
\hline Level $\mathrm{A}\left(k_{n}=0\right)$ & No visible degradation & - & - & - & $S_{w} \leq 1$ \\
\hline \multirow[t]{9}{*}{ Level $\mathrm{B}\left(k_{n}=1\right)$} & Visual or surface & - Surface dirt & 0.25 & $\leq 10$ & $1<S_{w} \leq 6$ \\
\hline & degradation & - Small surface craters & 0.60 & & \\
\hline & & - Wear or scratches & 0.60 & & \\
\hline & & - Crushing or scaling of the borders & 0.60 & & \\
\hline & & - Change of shine and/or colour & 0.60 & & \\
\hline & & - Damp stains & 0.60 & & \\
\hline & Cracking & - Cracked glazing & 0.25 & Independent of & \\
\hline & & $\begin{array}{l}\text { - Markedly orientated cracking }(<0.2 \mathrm{~mm})^{\mathrm{b}} \\
\text { without leakage }^{\mathrm{a}}\end{array}$ & 1.00 & the affected area & \\
\hline & Joint deterioration & - Staining or change in colour & 0.25 & $\begin{array}{l}\text { Independent of the } \\
\text { affected area }\end{array}$ & \\
\hline \multirow[t]{13}{*}{ Level C $\left(k_{n}=2\right)$} & Visual or surface & - Small surface craters & 0.60 & $>10$ and $\leq 50 \leq 30$ & $6<S_{w} \leq 20$ \\
\hline & degradation & - Wear or scratches & 0.60 & & \\
\hline & & - Crushing or scaling of the borders & 0.60 & & \\
\hline & & - Change of shine and/or colour & 0.60 & & \\
\hline & & - Damp stains & 0.60 & & \\
\hline & & - Biological growth & 1.00 & & \\
\hline & & - Efflorescence & 1.00 & & \\
\hline & Cracking & - Cracking with no predominant direction & 1.00 & $\leq 30$ & \\
\hline & & $\begin{array}{l}\text { - Markedly orientated cracking }(>0.2 \mathrm{~mm})^{c} \\
\text { without leakage }^{\mathrm{a}}\end{array}$ & 1.00 & & \\
\hline & Joint deterioration & - Without loss of filling material & 1.00 & $\leq 30 \leq 10$ & \\
\hline & & - With loss of filling material & 1.50 & & \\
\hline & Detachment & - Loss of adherence & 1.50 & $\leq 20 \leq 20$ & \\
\hline & & - Swelling & 1.50 & & \\
\hline \multirow[t]{14}{*}{ Level $\mathrm{D}\left(k_{n}=3\right)$} & Visual or surface & - Small surface craters & 0.60 & $>50>30$ & $20<S_{w} \leq 50$ \\
\hline & degradation & - Wear or scratches & 0.60 & & \\
\hline & & - Crushing or scaling of the borders & 0.60 & & \\
\hline & & - Change of shine and/or colour & 0.60 & & \\
\hline & & - Damp stains & 0.60 & & \\
\hline & & - Biological growth & 1.00 & & \\
\hline & & - Efflorescence & 1.00 & & \\
\hline & Cracking & - Cracking with no predominant direction & 1.00 & $>30$ and $\leq 50$ & \\
\hline & & $\begin{array}{l}\text { - Markedly orientated cracking }(>1 \mathrm{~mm})^{\mathrm{d}} \\
\text { without leakage }^{\mathrm{a}}\end{array}$ & 1.00 & & \\
\hline & Joint deterioration & - Without loss of filling material & 1.00 & $>30$ and $\leq 50$ & \\
\hline & & - With loss of filling material & 1.50 & $>10$ and $\leq 30$ & \\
\hline & Detachment & - Loss of adherence & 1.50 & $>20$ & \\
\hline & & - Swelling & 1.50 & $>20$ & \\
\hline & & - Localized detachment & 2.00 & $\leq 10$ & \\
\hline \multirow[t]{5}{*}{ Level $\mathrm{E}\left(k_{n}=4\right)$} & Cracking & - Cracking with no predominant direction & 1.00 & $>50$ & $S_{w}>50$ \\
\hline & & - Markedly orientated cracking $(>5 \mathrm{~mm})^{\mathrm{e}}$ & 1.00 & & \\
\hline & Joint deterioration & - Without loss of filling material & 1.00 & $>50$ & \\
\hline & & - With loss of filling material & 1.50 & $>30$ & \\
\hline & Detachment & - Generalized detachment & 2.00 & $>10$ & \\
\hline
\end{tabular}

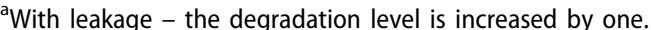

${ }^{\mathrm{b}}$ Cracking, detectable at a distance greater than $5 \mathrm{~m}$ only if binoculars are used.

'Tenuous cracking line, easily detectable at a distance greater than $5 \mathrm{~m}$, using binoculars.

'Well defined cracking visible from a distance of more than $5 \mathrm{~m}$, without using binoculars.

${ }^{e}$ Cracking characterized by a thick line in which a clear separation of the borders can be seen, from a distance of more than $5 \mathrm{~m}$, with the aid of binoculars.
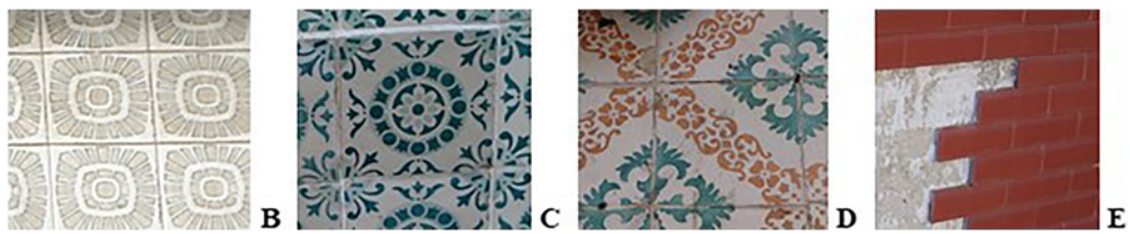

Figure 2. Illustrative example of the visual condition of ceramic claddings in each degradation level.

and repair of ceramic claddings. It is considered that the degradation process follows a deterioration scale with five discrete states from new (level A) to failed (level E). Furthermore, it is assumed that the condition of the façades is hidden and is only revealed at the time of inspections. These inspections are performed at regular intervals defined by the asset owner or manager.
In order to reduce the deterioration rate or improve the performance of the façade, maintenance actions are considered during the claddings' life-cycle. A successful maintenance program seeks a balance between conservation and rehabilitation activities. Therefore, two main types of maintenance actions are considered: preventive and corrective. Preventive maintenance actions usually lead to lower impact 
in the claddings' performance and lower costs, while corrective maintenance actions can significantly increase the claddings' performance but also encompass a higher economic burden (van Noortwijk \& Frangopol, 2004). A combination of both types of maintenance is usually required to achieve a cost-effective life-cycle performance.

Currently, the concept of condition-based maintenance is increasingly relevant, which suggests that any maintenance action should be preceded by an inspection to evaluate the current observed degradation condition of the component under analysis (Liao, Elsayed, \& Chan, 2006). In this sense, in this study, preventive maintenance actions are applied at regular time intervals over the cladding's lifetime. Herein, it is assumed that preventive maintenance actions are not applied before an inspection is performed. On the other hand, corrective maintenance actions are applied when an inspection reveals that the condition of the façade has crossed a predefined threshold.

Therefore, the scheduling of maintenance actions is performed after an inspection. During the inspection, the need for a corrective maintenance action is evaluated. If a corrective action is required, its effect is included in the performance model, and no further action is taken until the next inspection. On the contrary, it is checked if any preventive maintenance was scheduled since last inspection, otherwise no further action is taken until the next inspection.

Each maintenance action is assumed to be modelled by one or more than one of the following effects (Neves \& Frangopol, 2005):

1. Improvement of the condition state of the façade after the application of the maintenance action;

2. Suppression of the deterioration process for a period of time after the application of the maintenance action;

3. Reduction of the deterioration rate for a period of time after the application of the maintenance action.

Figure 3 depicts the different impacts of the maintenance actions on the façades. When a maintenance that improves the condition state is applied, this effect is described by the indication of the condition state for which the façade improves immediately after the maintenance, $\gamma$, as illustrated in Figure $3(\mathrm{a})$. On the other hand, if the maintenance suppresses the deterioration process, this is characterized only by the time period during which the process is suppressed, $t_{d}$. During this time, it is assumed that the performance indicator of the façade remains unchanged, as shown in Figure 3(b). Finally, if the maintenance reduces the rate of deterioration, this is characterized by two parameters: the period of time that the deterioration rate is affected, $t_{r}$; and the deterioration factor, $\delta$. These two parameters allow reducing the deterioration rate of the façade, as displayed in Figure 3(c).

\subsection{Maintenance model}

The complete Petri net maintenance model used to evaluate the performance of ceramic claddings is shown in Figure 4(a). The meaning of each part of the model is described in the following sections.
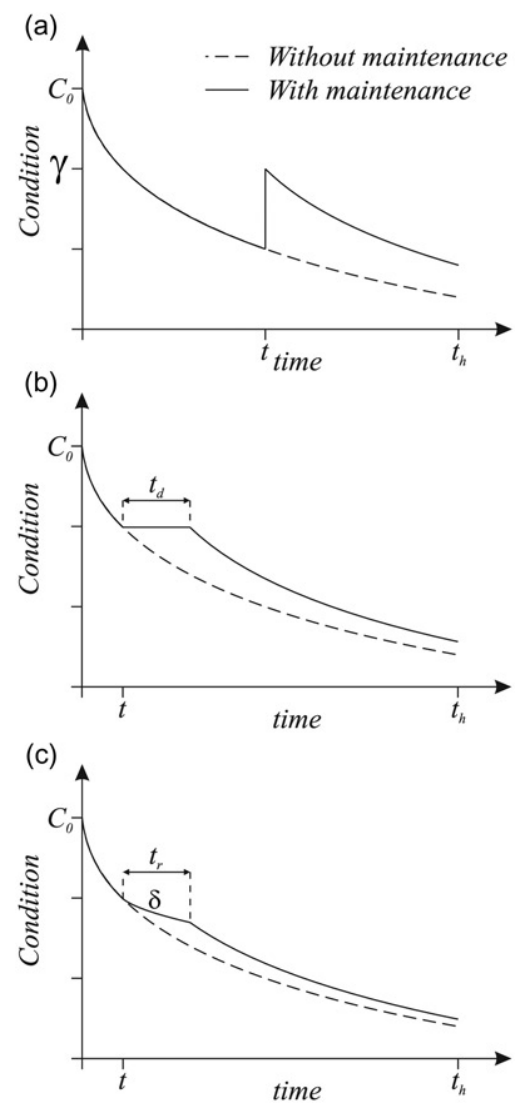

Figure 3. Effects of maintenance: (a) improvement of the condition state; (b) suppression of the deterioration process; and (c) reduction of the deterioration rate.

\subsubsection{Deterioration process}

The deterioration process is modelled through a linear sequence of places, adopting stochastic timed transitions, where each place represents a condition level of the classification system adopted (Andrews, 2013; Yianni, Rama, Neves, Andrews, \& Castlo, 2017). The stochastic timed transitions are located between places, specifying the transition times of moving between different condition levels.

Under no maintenance, the condition of the ceramic claddings deteriorates continuously over time until the worst condition level defined in the performance scale is reached. Timed transitions are used to model the sojourn time in each deterioration level (i.e. the time that the ceramic cladding spends in deterioration level $i$ before moving to deterioration level $i+1)$. In Figure 4(a), the deterioration process is depicted by five places $\left(p_{1}\right.$ to $\left.p_{5}\right)$ and four transitions $\left(t_{1}\right.$ to $t_{4}$ ), where places $p_{1}$ and $p_{5}$ represent, respectively, the best and worst condition state of the qualitative performance scale. The remaining places represent the intermediate condition levels and the position of the token in the net indicates the current condition level of the cladding.

\subsubsection{Inspection process}

The deterioration level of a ceramic cladding is not continuously known; the process can be considered unobserved until an inspection occurs, when the cladding's condition is revealed. The inspections are periodic and carried out within the maintenance program defined. In general, these visual inspections 
are performed by specialized technical staff with the aim of evaluating the degradation state of the cladding through the identification of anomalies that may affect its performance. An inspection enables the adoption of the most appropriate maintenance work to be requested for tackling existing anomalies with the appropriate priority. The section of the maintenance model that is responsible for scheduling the time inspections is shown in Figure 4(a) through the cycle formed by the following places and transitions: $p_{6}-t_{6}-p_{7}-t_{5}-p_{6}$.

A token in place $p_{6}$ means that an inspection is not required or should not be performed at that time. Furthermore, the presence of a token in place $p_{6}$ allows enabling transition $t_{6}$. This transition is a stochastic timed transition and manages the time intervals between inspections, $\theta$. When transition $t_{6}$ fires, after $\theta$ time units, the token is removed from the place $p_{6}$ and is added to place $p_{7}$.

A token in place $p_{7}$ means that it is time to perform an inspection, enabling several actions. First, it enables one of the following transitions: $t_{7}$ to $t_{11}$. The firing of one of these transitions removes the token from the deterioration process (places $p_{1}$ to $p_{5}$ ) and reveals the true condition of the ceramic cladding by placing it in one of the following places $p_{8}$ to $p_{12}$, respectively. A token in places $p_{8}, p_{9}, p_{10}, p_{11}$ or $p_{12}$ means, respectively, that the true condition of the ceramic cladding is A, B, C, D or E. Place $p_{7}$ is connected to transitions $t_{7}$ to $t_{11}$ by bidirectional arcs, representing a simplification for two unidirectional arcs. This ensures that the token in place $p_{7}$ is not removed at this stage. After that, the immediate transition $t_{5}$ is enabled (once the inhibitor arc constraints of the places $p_{1}$ to $p_{5}$ are checked), which causes the token placed in place $p_{7}$ to return to place $p_{6}$ to wait for the next inspection.

\subsubsection{Maintenance process}

Once the condition of the ceramic cladding is revealed, the required maintenance works can be established. The maintenance process is illustrated in Figure 4 (a) by places $p_{13}$ to $p_{26}$ and transitions $t_{12}$ to $t_{34}$. As mentioned above, the existence of a token in one of the places $p_{8}-p_{12}$ means that the condition of the ceramic cladding is known, and the maintenance works can be initiated. The first step is to analyse what types of maintenance action are available in the maintenance program, according to the observed condition. This information is introduced in the model through places $p_{13}$ to $p_{22}$. A token in places $p_{13}-p_{17}$ means that a preventive maintenance must be done, while a token in places $p_{18}-p_{22}$ means that a corrective maintenance is needed. If there is no token in these places, then the degradation condition of the cladding does not require the performance of a maintenance action. On the other hand, in cases where tokens are placed in both types of maintenance, corrective maintenance is performed, since this type of maintenance is more effective and usually covers the same maintenance works as preventive maintenance.

Subsequently, depending on the action to take, one of the following transitions may be firing:

- Transitions $t_{12}-t_{16}$ : No maintenance is performed, the token is removed from the observed condition places $\left(p_{8}-p_{12}\right)$ and deposited in place $p_{23}$.
- Transitions $t_{17}-t_{21}$ : Preventive maintenance is applied, the tokens are removed from the observed condition places $\left(p_{8}-p_{12}\right)$ and from preventive maintenance places $\left(p_{13}-p_{17}\right)$, and deposited in place $p_{24}$.

- Transitions $t_{22}-t_{26}$ : Corrective maintenance is applied, the tokens are removed from the observed condition places $\left(p_{8}-p_{12}\right)$ and from corrective maintenance places $\left(p_{18}-p_{22}\right)$, and deposited in place $p_{25}$.

A token arriving at place $p_{23}$ means that no maintenance is performed, and the condition of the cladding is the one observed during the inspection. On the other hand, a token in place $p_{24}$ means that an inspection has been performed, the true condition of the ceramic cladding has been revealed and a preventive maintenance action is required. The same applies to place $p_{25}$ for a corrective maintenance action.

Places $p_{23}-p_{25}$ enables, respectively, transitions $t_{27}-t_{29}$, which move the token to place $p_{26}$. This place is a decision place, since it enables five immediate transitions $t_{30}-t_{34}$ that conflict with each other. The choice of the transition to fire is performed in a deterministic way, according to the effect of the maintenance action on the ceramic cladding. In this model, the application of preventive and corrective maintenance was considered 'instantaneous' through the use of reset transitions $t_{28}$ and $t_{29}$, respectively. However, a transitions delay can be added in order to model, in a more realistic way, the time required for the performance of maintenance interventions.

\subsubsection{Preventive maintenance actions}

The characteristics of the preventive maintenance are introduced in the maintenance model through places $p_{27}$ to $p_{29}$ and transitions $t_{35}$ to $t_{39}$ (Figure $4(\mathrm{a})$ ). The marking of places $p_{27}$, $p_{28}$ or $p_{29}$, means, respectively, that the maintenance actions, when applied, have the effect of improving the condition of the cladding, suppressing of the deterioration process or reducing the deterioration rate. Then, depending on the impact of the maintenance action on the cladding's condition, only one of the following immediate transitions can fire by removing the token from place $p_{24}$ and placing it in place $p_{30}$ :

- Transition $t_{35}$ : Improvement of the condition only.

- Transition $t_{36}$ : Suppression of the deterioration process over a period of time only.

- Transition $t_{37}$ : Improvement of the condition state and suppression of the deterioration process over a period of time.

- Transition $t_{38}$ : Reduction of the deterioration rate over a period of time only.

- Transition $t_{39}$ : Improvement of the condition state and reduction of the deterioration rate over a period of time.

The values of the parameters needed to model maintenance are 'attached' to the tokens present in places $p_{27}$ to $p_{29}$. When the transition fire occurs, this information is communicated to the token placed in $p_{30}$, which is responsible for introducing the characteristics of the maintenance implemented in the deterioration process of the maintenance model. 


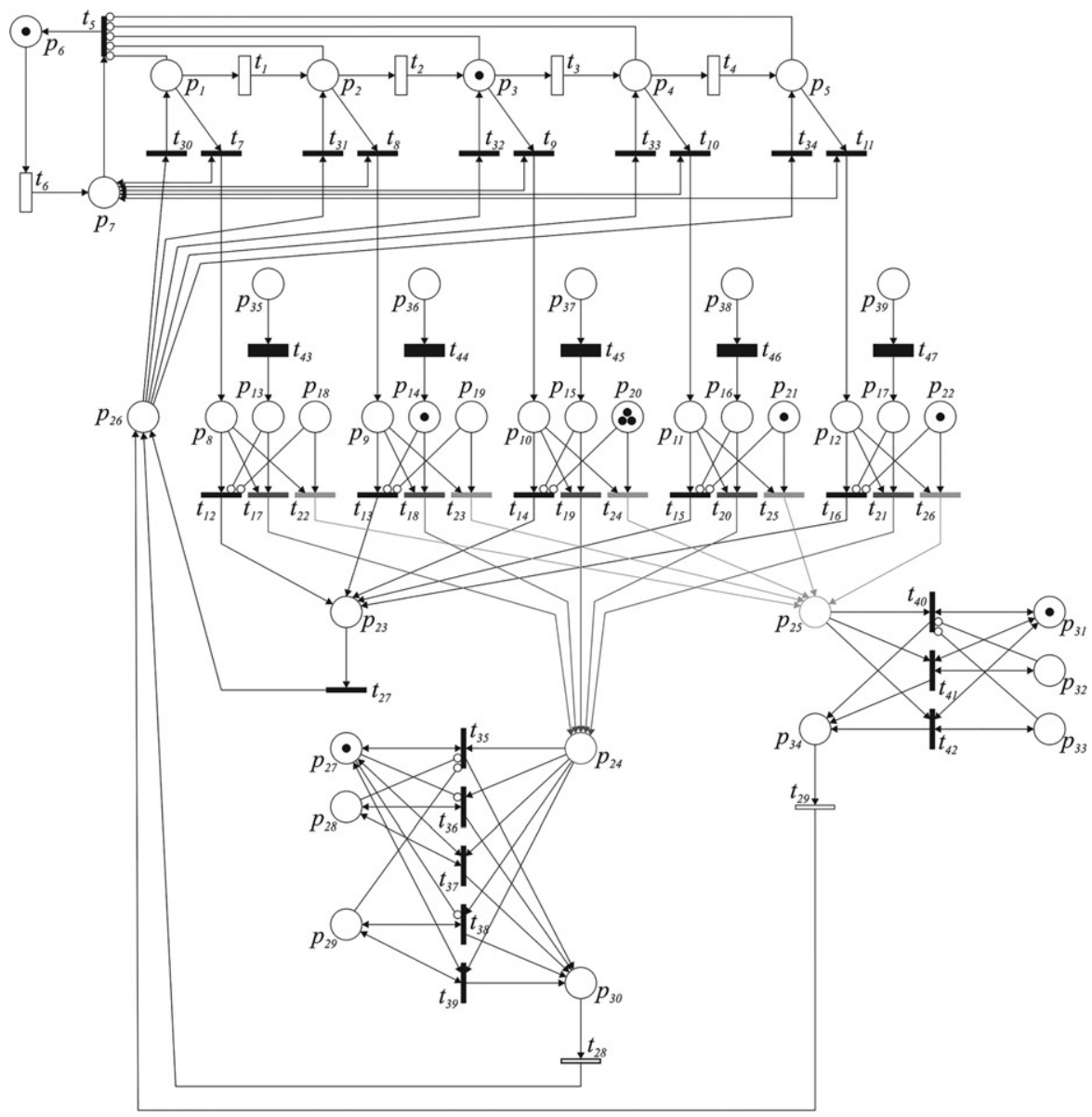

(a)

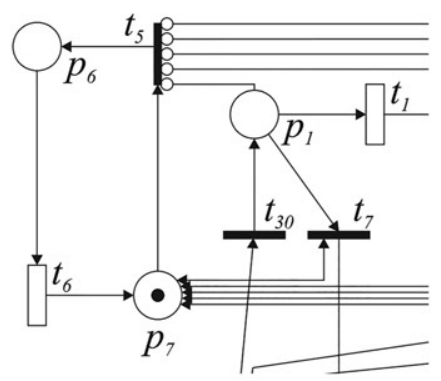

(b)

Figure 4. Petri net scheme of the complete maintenance model proposed. (a) Complete Petri net scheme; (b) After the fire of transition $t_{6}$ - inspection process is initiated; (c) After the fire of transition $t_{9}$ - the condition of the cladding is revealed to be $C_{\text {; }}(d)$ After the fire of transition $t_{5}$ - the inspection process is finished; (e) After the fire of transition $\mathrm{t}_{24}$ - the maintenance action to apply is chosen (a minor intervention is performed); ( $f$ ) After the fire of transition $\mathrm{t}_{40}$ - the maintenance effects are computed (minor intervention improves the condition level); $(\mathrm{g})$ After the fire of transition $\mathrm{t}_{29}$ - the maintenance action is applied; ( $\mathrm{h}$ ) After the fire of transition $\mathrm{t}_{30}$ - the return of the cladding to the deterioration process.

\subsubsection{Corrective maintenance actions}

For corrective maintenance, the same methodology was followed as in preventive maintenance. The characteristics of the maintenance are introduced in the maintenance model through places $p_{31}$ to $p_{33}$ and transitions $t_{40}$ to $t_{42}$ (Figure $4(\mathrm{a})$ ). Then, depending on the impact that maintenance has on the ceramic claddings, only one of the following immediate transitions can fire by removing the token from place $p_{25}$ and depositing it in place $p_{34}$ :

- Transition $t_{40}$ : Improvement of the condition state only.

- Transition $t_{41}$ : Improvement of the condition state and suppression of the deterioration process over a period of time.
- Transition $t_{42}$ : Improvement of the condition state and reduction of the deterioration rate over a period of time.

The Petri net schemes for corrective maintenance and preventive maintenance are conceptually different, since preventive maintenance is considered as imperfect, and do not bring the cladding to the good-as-new state, i.e., in some situations some preventive actions do not trigger the transition of the cladding's degradation condition to a more favourable one. On the contrary, in this study, it is considered that corrective maintenance always improves the condition state of system, thus there will be a smaller combination of effects. 


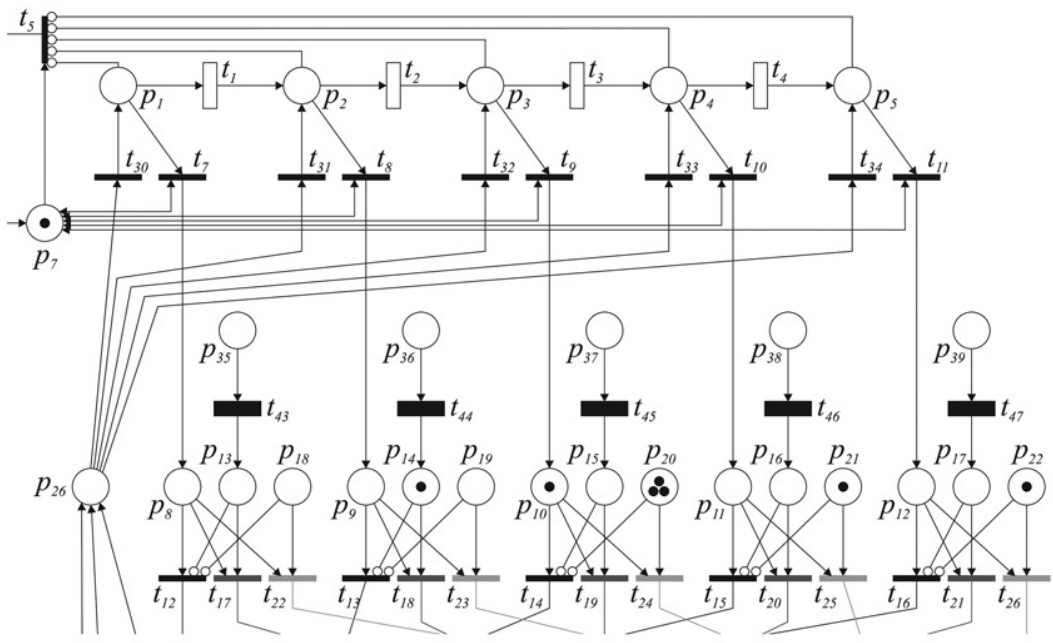

(c)

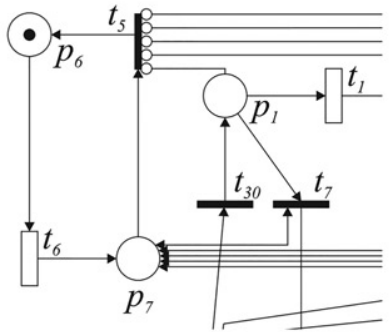

(d)

Figure 4. (Continued).

It should be mentioned that an almost unlimited number of combinations of effects and maintenance strategies can be modelled. This can be accomplished by introducing more transitions in the Petri net scheme of preventive and corrective maintenance. The combinations of effects of maintenance actions performed in ceramic claddings presented in this model represents only one example of the efficiency and flexibility of Petri nets.

\subsubsection{Periodicity of the preventive maintenance}

In this model, the periodicity of the preventive maintenance is considered through places $p_{35}-p_{39}$ and deterministic timed transitions $t_{43}-t_{47}$ (Figure 4(a)). The introduction of information that this maintenance is available in a given condition level is performed by placing tokens in places $p_{35}-p_{39}$. Transitions $t_{43}-t_{47}$ are associated with a delay that allows at the end of $\theta$ time units that the tokens present in places $p_{35}-$ $p_{39}$ are removed and added to places $p_{13}-p_{17}$, allowing preventive maintenance to be performed at the next inspection time, if the imposed constrains are verified.

\subsubsection{Renewal process}

At a given time, the deterioration of the ceramic claddings will reach a state where a specific maintenance action is no longer effective, and partial or total replacement of the cladding is required. The instant after which a specific maintenance action is no longer effective can be defined in several ways, namely: i) after a predetermined lifetime; ii) after the cladding achieves a condition level that portrays an unacceptable level of performance; and or iii) after a set number of maintenance actions (Le and Andrews, 2016a). In Petri nets, any of these approaches can be implemented.

In this study, each maintenance action could only be applied a given number of times. These constrains are introduced in the model by adding to places $p_{35}-p_{39}$ (preventive maintenance), and places $p_{18}-p_{22}$ (corrective maintenance), a number of tokens equal to the maximum number of maintenance actions allowed. When the maximum limit of a maintenance action is reached, this action is no longer available, and the ceramic cladding continues deteriorating until the worst condition level is reached, where a more extensive maintenance action is required. Transitions $t_{28}$ and $t_{29}$ (reset transitions) initializes the tokens in places $p_{35}-p_{39}$ and $p_{18}-p_{22}$.

\section{Application of the proposed model to ceramic claddings}

\subsection{Maintenance strategies}

The methodology, previously described, was applied to analyse the deterioration of ceramic claddings over their lifetime. In this study, three maintenance strategies are considered. The proposal maintenance actions have three interventions levels: cleaning operations; minor; and major interventions. The different strategies were defined based on previous works and on experts' judgement.

Cleaning is considered a preventive maintenance action, which includes the scaffolding installation, cleaning with water jet and brushing. This action should contribute to an 


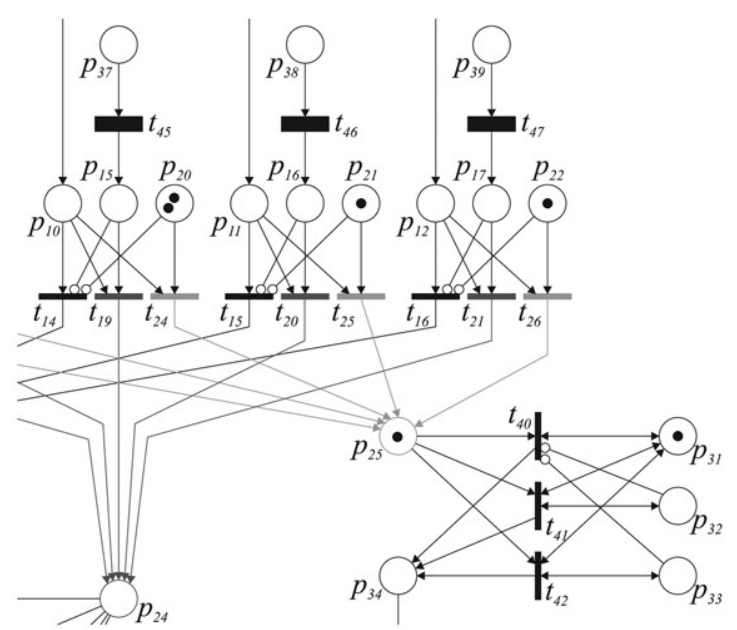

(e)

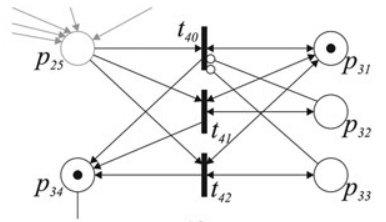

(f)

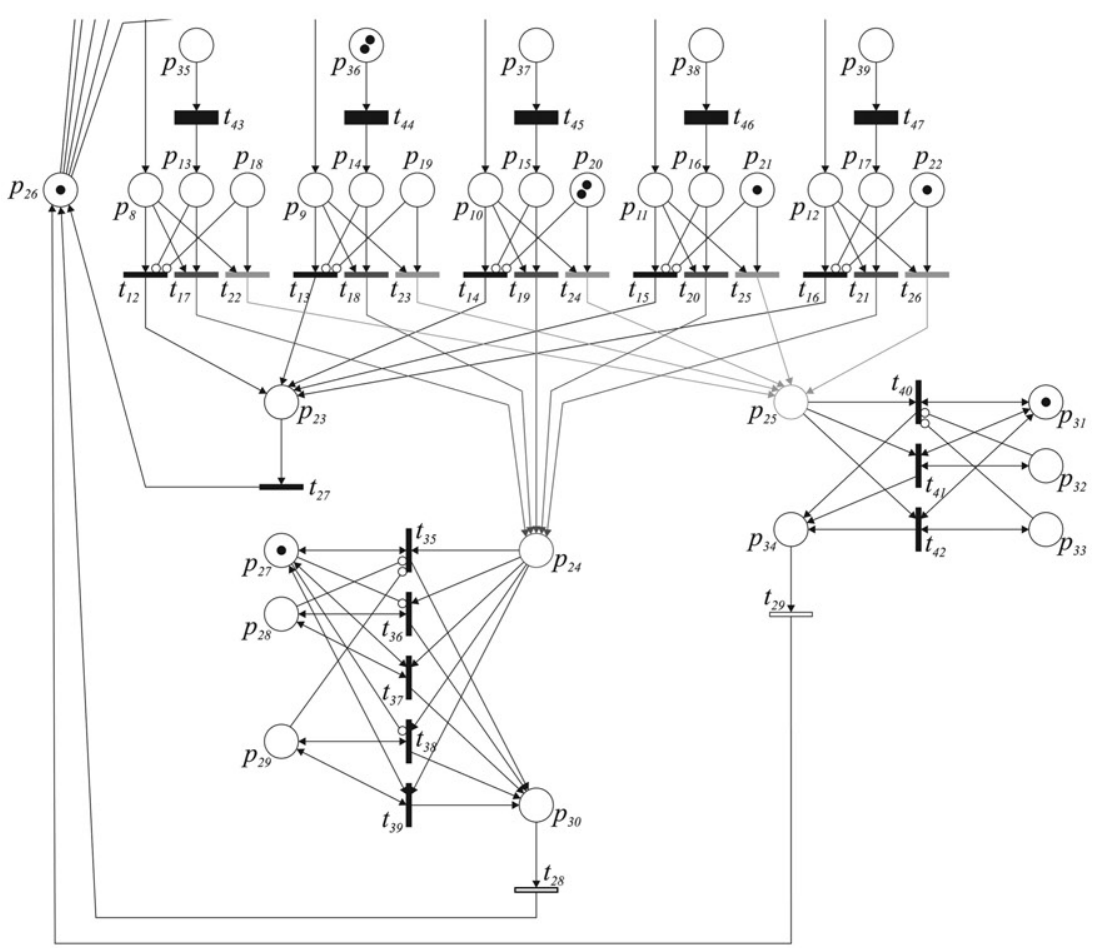

(g)

Figure 4. (Continued).

effective removal of debris and contaminants (aesthetical anomalies), preventing the deterioration of ceramic claddings. Numerically, this maintenance action is applied whenever an inspection is performed, and when the cladding is in level B but the last maintenance action has been applied more than 10 years before.

The existing maintenance models for deteriorated components have been limited to perfect maintenance actions (Bérenguer, Grall, Dieulle, \& Roussignol, 2003; Dieulle,
Bérenguer, Grall, \& Roussignol, 2003), thus, considering that a given maintenance action is able to restore the component for good-as-new, neglecting the residual degradation of the component under analysis. Nevertheless, when modelling the degradation of components under real in-use conditions, the maintenance actions not always restore the component to as-good-as-new condition. In this study, the effects of cleaning actions in the ceramic claddings were thoroughly analysed. In some situations, the cleaning actions 


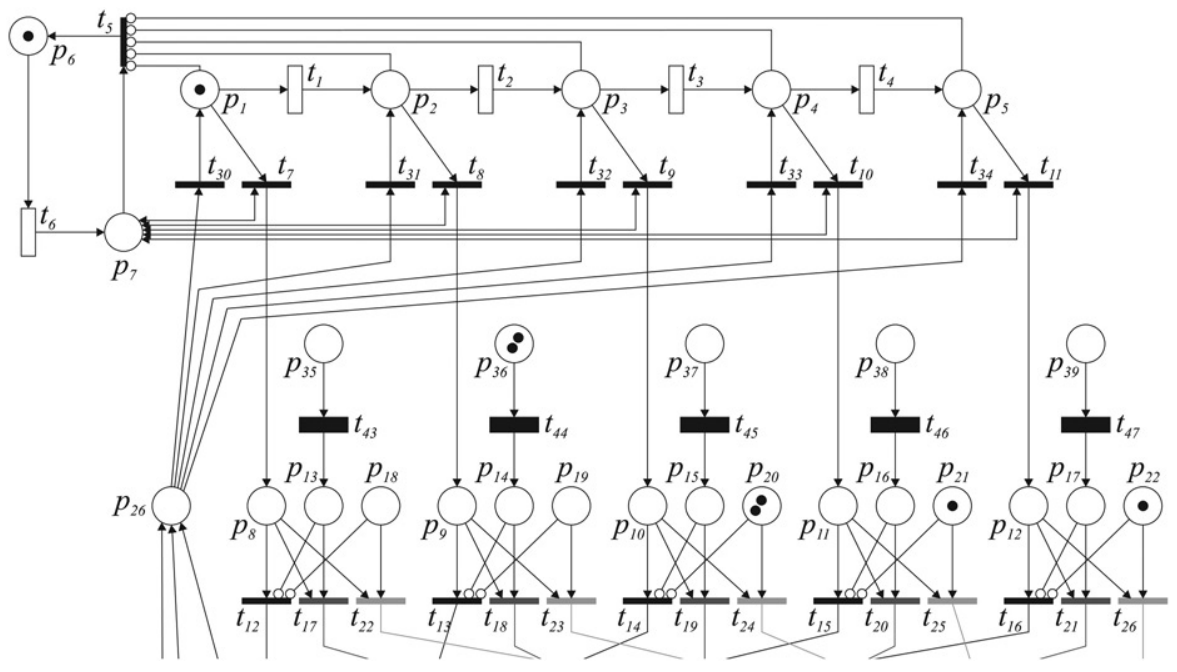

Figure 4. (Continued).

really improve the degradation state of the ceramic cladding, leading to the return to the initial condition (A). However, in some situations, the cleaning action only delays the degradation of the cladding, not repairing already existing problems such cracking. In this sense, a cleaning action is unable to reset the cladding's condition to the initial condition (A). In the sample analysed, the effects of a cleaning action are examined, trying to evaluate its impact on the overall condition of the claddings. The analysis of the results revealed that this action improves the condition to level A with a probability of $31.4 \%$ or causes no significant improvement, $P=68.6 \%$.

The minor intervention is considered a corrective maintenance action, which encompasses the repair and localized replacement of ceramic tiles. In the minor intervention, the following actions are performed: i) $20 \%$ of the ceramic tiles are replaced; ii) $30 \%$ of the cracking are filled; iii) $10 \%$ of joints are replaced; and iv) the cladding is subjected to a cleaning action. The analysis of the impact of the application of maintenance actions in ceramic claddings is a complex task, and there is a lack of information regarding the actions performed on the sample analysed, during the claddings' life cycle.

In this manner, usually, the degradation models neglect the effects of maintenance actions, considering that a maintenance action can restart the claddings' life cycle. However, in reality, usually, the actions performed intend to achieve a balance between improving the cladding's performance and minimizing the related maintenance costs, and it is acceptable for the stakeholders that some damage remains after maintenance. This fact was modelled herein by assuming that a ceramic cladding in an intermediate deterioration level (C) has a probability of $50 \%$ of restoring its original condition (go to condition A, after the maintenance action) and a probability of $50 \%$ of improving its condition to $\mathrm{B}$.

Finally, the major intervention is computed as a renewal process, applied when the claddings present an unacceptable degradation level. In other words, this intervention is only applied when the ceramic claddings reach the end of their service life, and therefore, the entire cladding must be replaced. In the maintenance model proposed, a ceramic cladding reaches the end of its service life when the deterioration level reaches level D or higher. The condition level after which the ceramic claddings reach the end of their service life has been defined and discussed in previous studies (Ferreira et al., 2019; Silva, de Brito et al., 2016). In this study, the claddings' replacement causes it to return to condition A or B. In perfect conditions, the cladding should return to 'as good as new' condition (A), however, in some particular situations, due to execution errors or inadequate maintenance, the cladding only returns to level $\mathrm{B}$.

Figure 5 presents an illustrative example of a case study, before and after intervention, in which the replacement of ceramic tiles does not lead to the cladding's returning to the initial condition. Unfortunately, this type of replacement is quite common in real-world practice, which consists in the replacement of the ceramic tiles, replacing the bonding material and filling the joints, but maintaining the degradation condition of the ceramic tiles (all visual anomalies, e.g., stains, efflorescence, biological colonization).

To evaluate the performance of this material without and with maintenance actions, three maintenance strategies were defined:

i. Maintenance strategy 1 - major intervention.

ii. Maintenance strategy 2 - combination of minor and major interventions.

iii. Maintenance strategy 3 - combination of cleaning, minor and major interventions.

Maintenance strategy 1 is considered in this work to characterise the maintenance strategy currently implemented by most owners (Thai-Ker \& Chung-Wan, 2006). In maintenance strategy 2, a minor intervention is also considered, to delay or mitigate the deterioration process without compromising important features of the building, and to prevent unnecessary disruption of the building's use (Forster \& 


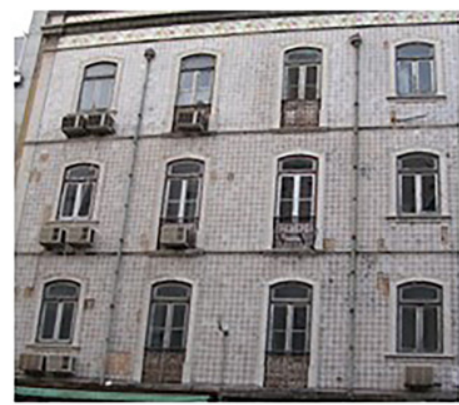

Before intervention, in 2014
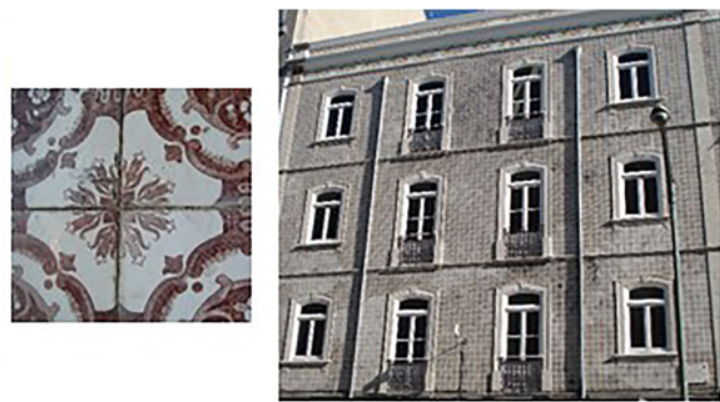

After intervention, in 2016

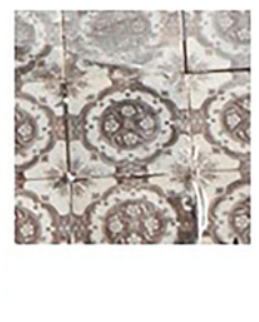

Figure 5. Illustrative example of a major intervention in which the initial condition was not restored.

Table 3. Parameters of the Weibull distributions adopted (Ferreira et al., 2019).

\begin{tabular}{lclcc}
\hline Transition & $t_{1}$ & \multicolumn{1}{c}{$t_{2}$} & $t_{3}$ & $t_{4}$ \\
\hline$\lambda_{i}$ & 7.0859 & 26.5108 & 23.2276 & 32.3015 \\
$\kappa_{i}$ & 1.0973 & 1.9847 & 19.6844 & 20.2604 \\
\hline
\end{tabular}

Kayan, 2009), showing that small repair works can be done to extend the service life of ceramic claddings. Finally, in maintenance strategy 3 , the inclusion of cleaning operations represents the main maintenance activity applied in ceramic claddings (Raposo, de Brito, \& Fonseca, 2013).

The transitions times that specify the movement between different deterioration levels of the ceramic claddings, denoted by transitions $t_{1}-t_{4}$ in Figure 4(a), are modelled as Weibull distributions with parameters $\left(\lambda_{i}, \kappa_{i}\right)$, with $i=1,2$, 3, 4, shown in Table 3, following the results obtained by Ferreira et al. (2019).

Regarding to periodicity of inspections, Silvestre and de Brito (2011) proposed an expert system for the inspection and diagnosis of ceramic claddings, referring that current visual inspections should be performed every 15 months to detect rapidly developing defects, and detailed inspections should be carried out every 5 years, and should include in situ nondestructive tests in addition to visual examination. More recently, Madureira, Flores-Colen, de Brito, and Pereira (2017) proposed a periodicity of inspections to external claddings of 3 years. Therefore, the inspection interval, $\theta$, is modelled as a triangular distribution with 3,4 , and 5, representing the minimum, mode, and maximum values, respectively.

The model depicted in Figure 4(a) includes immediate, deterministic and stochastic transitions. The deterioration, modelled by transitions $t_{1}$ to $t_{4}$, is stochastic, and each of these transitions is modelled using Weibull distribution. The time interval between inspections, modelled by transition $t_{6}$, is random and described by a triangular distribution with minimum, mode and maximum equal to 3,4 , and 5 years, respectively. Transitions $t_{43}$ to $t_{47}$, modelling the periodicity of the preventive maintenance (cleaning operations) are taken as deterministic and all other transitions are immediate.

In the maintenance strategies proposed in this study, the following assumptions are adopted: i) after two consecutive cleaning operations, this maintenance action is no longer efficient, and therefore a minor intervention should be performed, in order to repair the anomalies present in the ceramic claddings; ii) after three minor interventions, this maintenance action is no longer efficient, and it is necessary to apply a major intervention.

\subsection{Monte Carlo simulation}

Since there is significant uncertainty related to the assignment of a deterioration level to a ceramic cladding, as well as on the definition of the effects of maintenance actions, Monte Carlo simulation is used to consider the propagation of uncertainties during the ceramic cladding's lifetime and to compute the performance profiles.

The procedure used to determine the performance profile of the ceramic claddings for the situation where maintenance is considered is shown in Figure 6. The performance profile is characterized by initial condition state, $C_{0}$; deterioration rate vector, $\Theta$; time horizon, $t_{h}$; information regarding maintenance actions; and the interval between inspections, $t_{\text {insp }}$. The initial condition state, $C_{0}$, is used to define the initial marking of the Petri net, $M_{0}$, and the first transition of the deterioration process to fire, $t_{i}^{(k=1)}$; the deterioration rate vector, $\Theta$, is composed of the optimal parameters of the probability distribution used to model the deterioration process and is used to compute the sojourn time, $\tau^{(l)}$, in each deterioration level.

The sojourn time, $\tau^{(l)}$, is sampled using the inverse CDF of the Weibull distribution, given by:

$$
\tau_{i}^{(l)}=\lambda_{i} \cdot[-\ln (1-u)]^{1 / \kappa_{i}}
$$

where $\lambda_{i}$ and $\kappa_{i}$ are the parameters of the Weibull distribution with $i=1,2,3,4$ and $u$ is a uniformly distributed random variable between 0 and 1 ; the time interval between inspections, $t_{i n s p}^{(m)}$, is used to define the time that inspections should be performed on the ceramic claddings and the information regarding the maintenance actions is used to define the application range and the effects that these have on the ceramic claddings. The time interval between inspections, $t_{\text {insp }}^{(m)}$, is sampled using the inverse CDF of the triangular distribution, given by:

$$
t_{i n s p}^{(m)}=\left\{\begin{array}{c}
a+\sqrt{u \cdot(b-a) \cdot(c-a)}, \quad u \leq \kappa \\
c-\sqrt{(1-u) \cdot(c-a) \cdot(c-b)}, \quad u>\kappa
\end{array}\right.
$$


where $k=(b-a) /(c-a)$ and $a, b, c$ represent the minimum, mode, and maximum values of the distribution, respectively.

The first step in the procedure is the identification of the first transition to be fired, $t_{i}^{(k=1)}$, in the deterioration process and the sojourn time of the ceramic cladding in the current deterioration level, $\tau^{(l=1)}$, followed by the quantification of the time for the first inspection of the ceramic cladding, $t_{i n s p}^{(m=1)}$. The first time, $F T^{(n=1)}$, and its transition are computed through the minimum between the sojourn time, $\tau^{(l=1)}$, and the time of the first inspection, $t_{i n s p}^{(m=1)}$.

The main loop starts by checking whether the next firing time, $F T^{(n)}$, occurs after the time horizon, $t_{h}$, in which case the computation ends. Otherwise, the next transition to be fired can be either an inspection or a deterioration step. In the latter case, the enabled deterioration transition fires and the Petri net is updated. The procedure runs until the next firing time, $F T^{(n)}$, is larger than the time horizon. In each step, the first branch checks whether an inspection is computed and the relevant maintenance actions are applied. If no inspection occurs in that year, the next deterioration transition time is activated. The condition is updated and the next deterioration firing time, $\tau_{i}^{(k+1)}$, is computed. If the ceramic cladding is in the worst deterioration level, the transition time until the next deterioration step is taken as $\tau_{i}^{(k+1)}=\infty$.

The output of this procedure, in the time horizon, is a condition state vector, where the condition state of the ceramic cladding is defined for all years from the beginning of the analysis until the time horizon. The repetitive calculation from this procedure (Monte Carlo simulation) allows computing the mean and standard deviation of the deterioration level in each year.

Based on the assumptions defined above (Section 5.1), the maintenance strategies implemented can be linked with the Petri net scheme presented in Figure 4(a). When the first maintenance strategy is implemented, places $p_{1}, p_{6}, p_{21}$, $p_{22}$ and $p_{31}$ should be marked with one token each, at time $t=0$. A token in place $p_{1}$ indicates that ceramic claddings is, at time $t=0$, in deterioration level A; a token in place $p_{6}$ specifies that, at time $t=0$, it is not time to perform an inspection; a token in places $p_{21}$ and $p_{22}$ means, respectively, that a major intervention is a corrective maintenance and should be performed when the ceramic claddings is in deterioration level $\mathrm{D}$ or $\mathrm{E}$; and, finally, a token in place $p_{31}$ indicates that corrective maintenance improves the deterioration level of the ceramic claddings after the application of the maintenance action.

When the second maintenance strategy is applied, in addition to the places defined for strategy 1 , place $p_{20}$ should be marked with three tokens, at time $t=0$. The three tokens represent the assumptions adopted that after three minor interventions, this maintenance action is no longer efficient, and a major intervention should be performed. Finally, when the third maintenance strategy is employed, besides the places defined for strategies 1 and 2, places $p_{27}$ and $p_{36}$ should also be marked with one and two tokens, respectively, at time $t=0$. A token in place $p_{27}$ means that preventive maintenance improves the deterioration level of the ceramic claddings after the application of the maintenance action; and two tokens in place $p_{36}$ represent the assumptions adopted that, after two consecutive cleaning operations, this maintenance action is no longer efficient, and a minor or major intervention should be applied.

Therefore, to better explain the movement of tokens between places, consider, as an example, the marking shown in Figure 4(a) representing the system state at year 30, considering the third maintenance strategy and assuming the claddings is in deterioration level C. Furthermore, let us consider that transition $t_{3}$ fires at year 37 (i.e., instant that ceramic cladding deteriorates from level $\mathrm{C}$ to level D) and transition $t_{6}$ fires at year 32 (that is, the next inspection is performed at year 32).

According with these data, the next transition to fire is $t_{6}$. Figure 4(b) shows the distribution of tokens at time $t=$ 32 years, after transition $t_{6}$ fires. The token present in place $p_{6}$ is removed and a token is added to place $p_{7}$, meaning that an inspection is carried out. At this point, the unobserved deterioration process is revealed. This is modelled as the firing of transition $t_{9}$, revealing that the true condition of the cladding at year 32 is C (see Figure 4(c)). After the inspection, the token in place $p_{7}$ can return to place $p_{6}$ to wait for the next inspection (see Figure 4(d)). At this point, the time of the next inspection is sampled (it is assumed, in this example, that the next inspection will occur at year 36 ).

Next, the types of maintenance actions available in the maintenance program are analysed. The three tokens in place $p_{20}$ mean that a minor intervention should be performed. As shown in Figure 4(e), this corresponds to firing of transition $t_{24}$. Minor intervention improves the condition level, modelled as firing of transition $t_{40}$ (see Figure 4(f)). The condition of the cladding is updated, and the next deterioration time is computed (assumed at year 35). The application of minor intervention leads to firing of transition $\mathrm{t}_{29}$ (Figure $4(\mathrm{~g})$ ). This is a reset transition that updates the number of effective cleaning operations that can be applied. This leads to the computation of the time for the next cleaning operation. It is assumed that a cleaning operation is applied when the cladding is in level B but the last cleaning operation has been applied more than 10 years before. Since it is considered that a minor intervention includes a cleaning operation, transition $t_{44}$ will fire at year 42 .

Place $p_{26}$ is a decision place and enables the five immediate transitions $t_{30}-t_{34}$ that are in conflict with each other. The choice of the transition to fire is performed in a deterministic way, according to the effect of the maintenance action. Since the minor intervention improves the ceramic cladding to level $\mathrm{A}$, the next transition to fire is $t_{30}$, returning the token to the deterioration process. Figure $4(\mathrm{~h})$ illustrates the distribution of tokens at time $t=32$ years, after transition $t_{30}$ fires. The next transition to fire is $t_{1}$, because the deterioration of the ceramic cladding occurs before the next inspection.

In this study, a Monte Carlo simulation with a sample size of 50,000 was carried out, in order to obtain the following information:

1. The predicted future condition profile under the different maintenance strategies. 


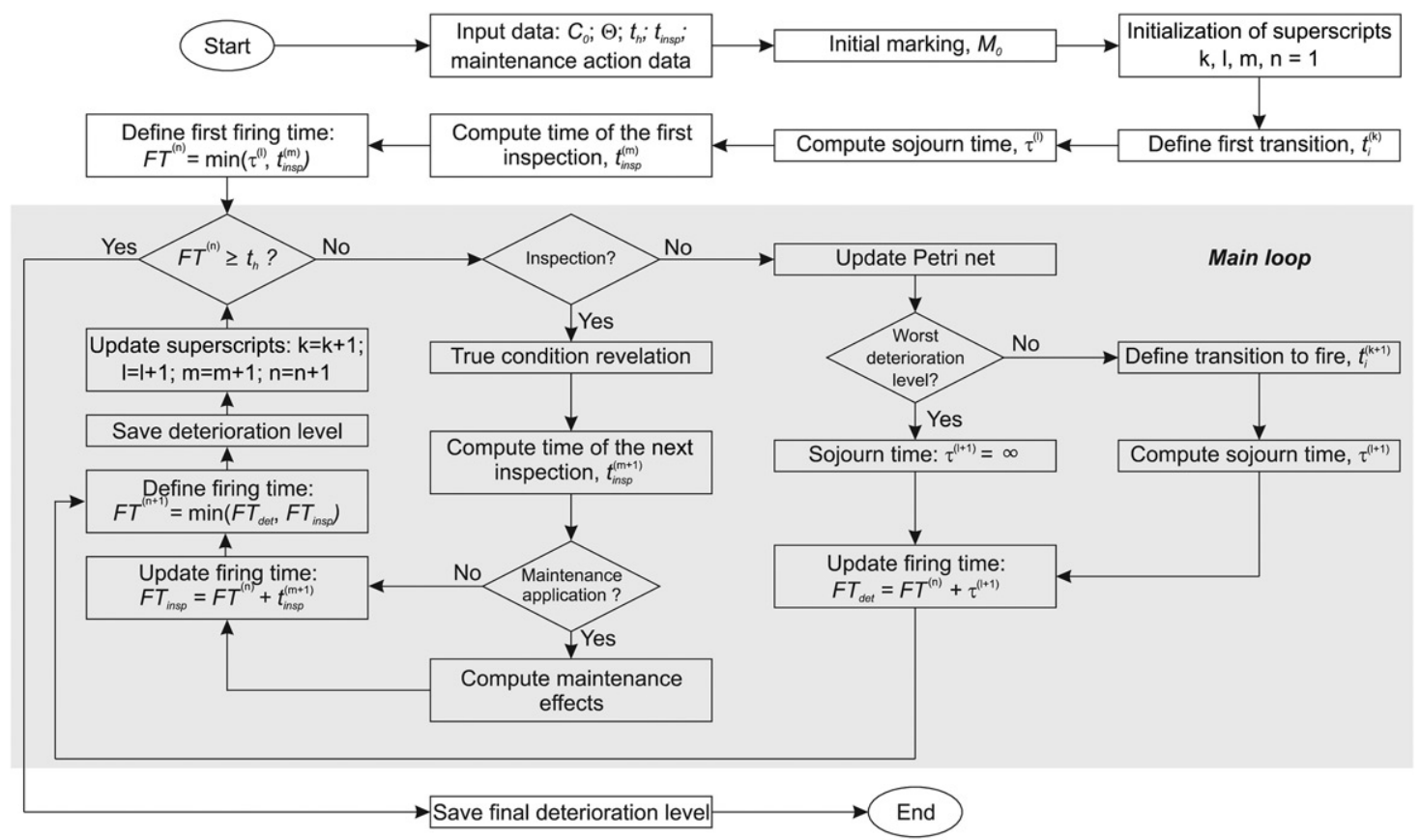

Figure 6. Procedure to compute the performance profile of the ceramic claddings over the time horizon for the maintenance scenario.

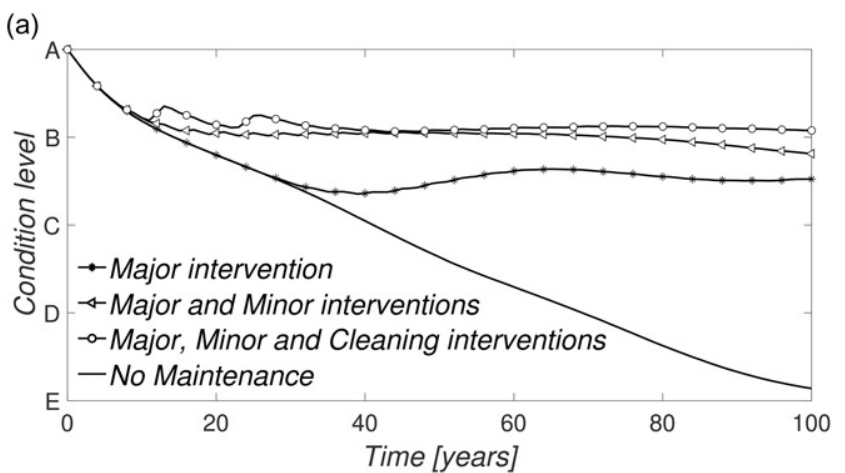

(b)

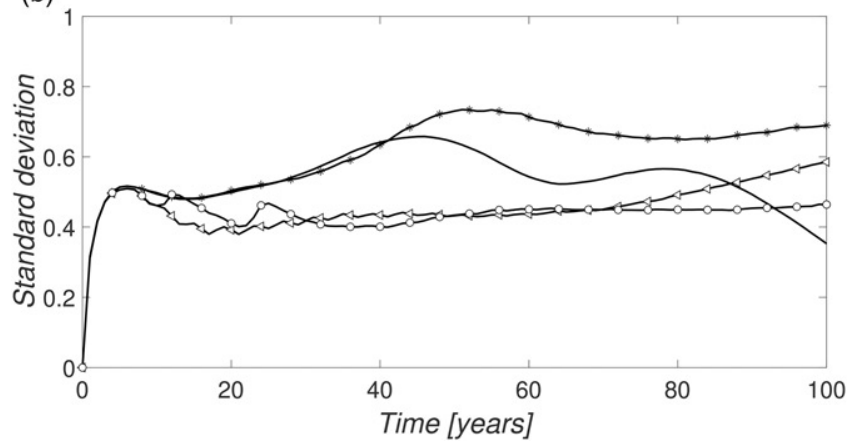

Figure 7. Comparison of the predicted future condition profile over time for all maintenance strategies considered: (a) mean condition level; and (b) standard deviation of the condition level. Mean and standard deviation are computed considering a correspondence between the condition scale and an integer scale between 1 and 5 .

2. The number of interventions (cleaning operations, minor and major interventions) performed in the cladding over the simulated lifetime, and the distribution of times of the application of each intervention during that period.

3. The cumulative cost profile of the different maintenance strategies, considering the annual discount rate.

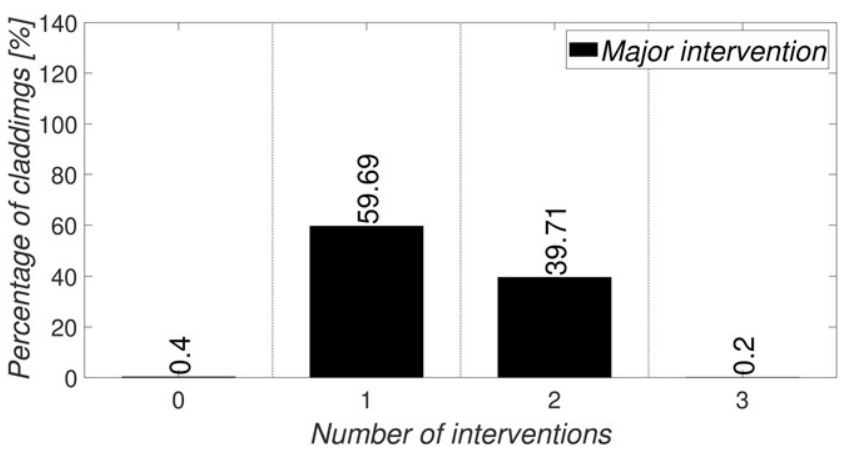

Figure 8. Number of interventions per cladding for strategy 1.

\subsection{Model results and discussion}

Considering a 100-year time horizon and a ceramic cladding in perfect conditions at the beginning of the analysis, the condition profile obtained for the three maintenance strategies and without maintenance are shown in Figure 7. The results obtained reveal that the proposed maintenance strategies have a significant impact on the mean degradation condition. In all cases, the mean condition level decreases beyond level B. In terms of standard deviation of the results, the values range, on average, between 0.4 and 0.8 , and strategy 1 shows the largest dispersion of results. When only major interventions are applied, the ceramic claddings are allowed to deteriorate significantly and rapidly, before maintenance is applied. As a consequence, the probability of the deterioration level being very high or very low is higher, resulting in high standard deviations. On the other hand, as preventive maintenance is applied, the deterioration is slowed down, meaning that ceramic claddings take longer to evolve from low to high deterioration levels and spend more time close to the mean condition, leading to a smaller standard deviation. 
Table 4. Statistics of the time of the first intervention (in years) for strategy 1.

\begin{tabular}{lccccc}
\hline Intervention & Minimum & Maximum & Average & $\begin{array}{c}\text { Standard } \\
\text { deviation }\end{array}$ & $\begin{array}{c}\text { Confidence } \\
\text { level of } 90 \%\end{array}$ \\
\hline Major & 22 & 100 & 55.3 & 13.7 & 74 \\
\hline
\end{tabular}

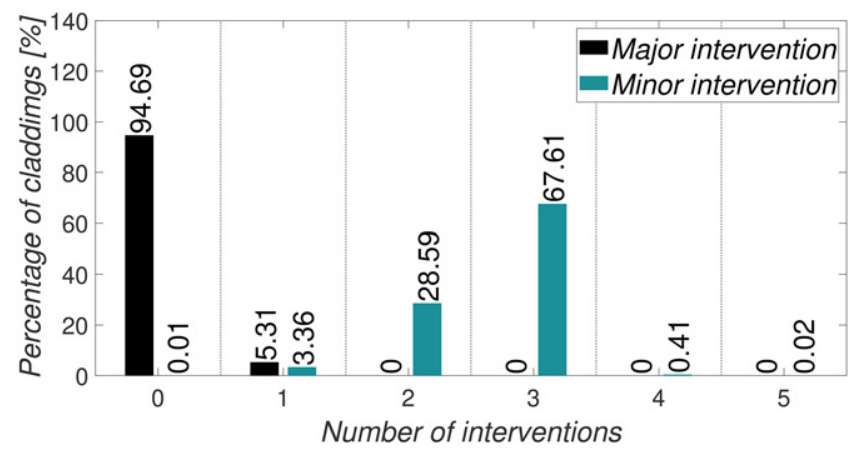

Figure 9. Number of interventions per cladding for strategy 2 .

Table 5. Statistics of the time of the first intervention (in years) for strategy 2.

\begin{tabular}{lllllc}
\hline Intervention & Minimum & Maximum & Average & $\begin{array}{l}\text { Standard } \\
\text { deviation }\end{array}$ & $\begin{array}{c}\text { Confidence } \\
\text { level of } 90 \%\end{array}$ \\
\hline Major & 55 & 100 & 91.9 & 7.3 & 99 \\
Minor & 4 & 98 & 32.8 & 13.8 & 52 \\
\hline
\end{tabular}

Table 6. Statistics of the time of the first intervention (in years) for strategy 3.

\begin{tabular}{lccccc}
\hline Intervention & Minimum & Maximum & Average & $\begin{array}{c}\text { Standard } \\
\text { deviation }\end{array}$ & $\begin{array}{r}\text { Confidence } \\
\text { level of } 90 \%\end{array}$ \\
\hline Major & 56 & 100 & 88.9 & 9.7 & 99 \\
Minor & 4 & 100 & 46.5 & 19.0 & 70 \\
Cleaning & 11 & 92 & 14.9 & 5.2 & 22 \\
\hline
\end{tabular}

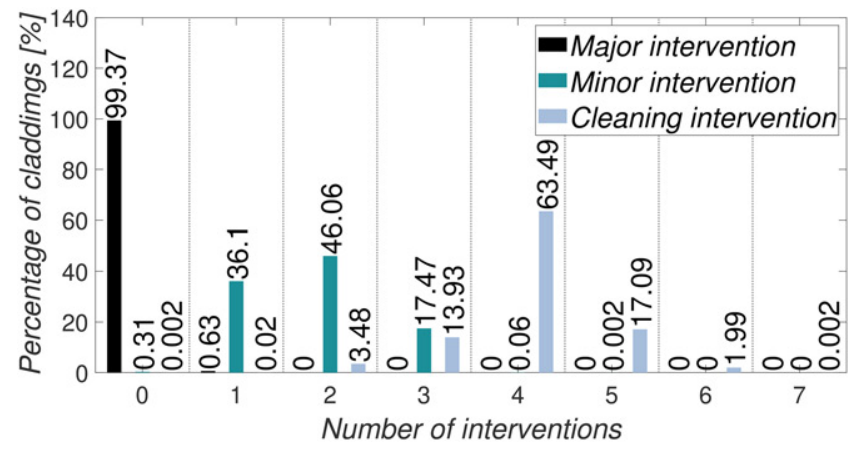

Figure 10. Number of interventions per cladding for strategy 3 .

According to Silva, de Brito, et al. (2016), the end of service life of a ceramic cladding varies between 46 and 58 years. Based on these values, in this study, the impact of the three maintenance strategies in the estimated service life of ceramic claddings is evaluated. As mentioned above, strategy 1 represents the maintenance strategy currently implemented by most owners. Figure 8 and Table 4 illustrate that, for a time horizon of 100 years, on average, 1.40 major interventions are performed per cladding, and the
Table 7. Fixed costs of the maintenance actions (data sourced from CYPE, 2016).

\begin{tabular}{lc}
\hline Intervention & Cost at year $0\left[€ / \mathrm{m}^{2}\right]$ \\
\hline Major & 52.15 \\
Minor & 22.59 \\
Cleaning & 9.13 \\
\hline
\end{tabular}

first intervention is applied approximately at year 55.3 (only $0.4 \%$ of the claddings are not replaced in the time horizon).

Figure 9 and Table 5 present, respectively, the distribution of the number of interventions by cladding and the statistics of the time of the first intervention for strategy 2 (major and minor intervention). These results show that, for a time horizon of 100 years, on average, 0.05 major interventions and 2.65 minor interventions are performed, per cladding. The first major intervention is performed approximately at year 91.9 (94.69\% of the claddings are not replaced in the time horizon) while the first minor intervention is applied, on average, at year 32.8 (only $0.01 \%$ of the claddings are not repaired in the time horizon). The results obtained for strategy 2 are in accordance with the values suggested by Silva, Gaspar, et al. (2016), which mentioned that minor maintenance actions should be performed before year 40. Furthermore, the combination of minor and major interventions increases the estimated service life, since the probability of the claddings not being replaced increases from $0.4 \%$ to $94.69 \%$.

According to the results of strategy 3, on average and until year 14.9 (Table 6), the ceramic claddings are only monitored, which agrees with the literature. Silva, Gaspar, et al. (2016) state that ceramic claddings should only be monitored until year 13 (only $0.002 \%$ of the claddings are not clean in the time horizon). Furthermore, comparing with strategy 2, the combination of cleaning, minor and major interventions also allows increasing the estimated service life, since the probability of the claddings not being replaced increases from $94.69 \%$ to $99.37 \%$. Figure 10 reveals that, for a time horizon of 100 years, on average, 0.006 major interventions, 1.81 minor interventions and 4.00 cleaning operations are performed per cladding.

Usually, the stakeholders are not only concerned with the claddings' performance or degradation condition, but mainly with costs. In this sense, the costs of the three maintenance strategies are examined in detail. For this purpose, the life-cycle costs are compared, focusing on the influence of direct costs and the annual discount percentage. An analysis of a future investment must consider the time value of money, so that the cost of an intervention depends on the moment the action is taken. In this context, the life-cycle maintenance cost must be converted by a discount rate to a predefined reference time. The present value at time zero can be computed as follows (Frangopol, Kallen, \& van Noortwijk, 2004):

$$
c_{0}=\frac{c_{t}}{(1+v / 100)^{t}}
$$

where $c_{t}$ is the cost at time $t$ and $v$ is the annual discount percentage. 
Table 8. Results obtained for the different strategies under analysis.

\begin{tabular}{|c|c|c|c|c|c|c|}
\hline $\begin{array}{l}\text { Maintenance } \\
\text { strategy }\end{array}$ & Actions performed & $\begin{array}{l}\text { Cumulative cost over } \\
100 \text { years With a } 5 \% \\
\text { discount rate }\left[€ / \mathrm{m}^{2}\right]\end{array}$ & $\begin{array}{l}\text { Cumulative cost over } \\
100 \text { years With a } 0 \% \\
\text { discount rate }\left[€ / \mathrm{m}^{2}\right]\end{array}$ & $\begin{array}{l}\text { Estimated } \\
\text { service } \\
\text { life (years) }\end{array}$ & $\begin{array}{l}\text { Increase in the } \\
\text { estimated service } \\
\text { life (years) }\end{array}$ & $\begin{array}{c}\text { Probability of application of } \\
\text { major interventions during } \\
\text { the time horizon }(\%)\end{array}$ \\
\hline 1 & Major interventions & 4.69 & 72.86 & 55.3 & - & 99.60 \\
\hline 2 & $\begin{array}{l}\text { Minor interventions } \\
\text { Major interventions }\end{array}$ & 7.87 & 62.66 & 91.9 & 36.6 & 5.31 \\
\hline 3 & $\begin{array}{l}\text { Cleaning Minor interventions } \\
\text { Major interventions }\end{array}$ & 12.14 & 77.72 & 88.9 & 33.6 & 0.63 \\
\hline
\end{tabular}

(a)

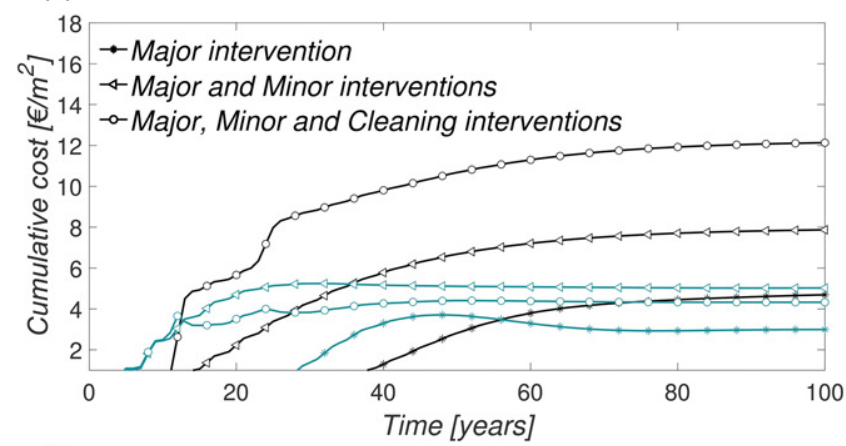

(b)

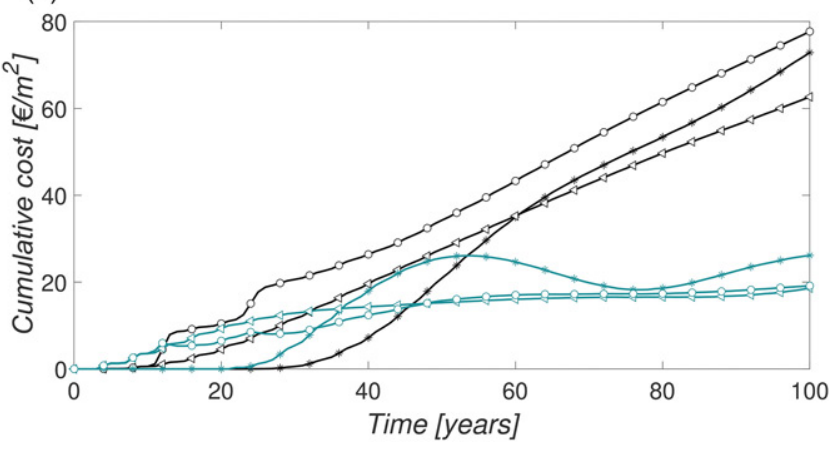

Figure 11. Cumulative cost profiles for the three maintenance strategies considered: (a) 5\% discount rate; and (b) $0 \%$ discount rate. Black lines represent the mean cumulative cost and grey lines the standard deviation of the mean cumulative cost.

The discount rate over long time periods is markedly difficult to predict. As a consequence, two extreme values were considered to evaluate the sensitivity of the results to this parameter. As mentioned by van Noortwijk and Frangopol (2004), the discounted cost is essentially used for balancing the initial cost of investment against the future cost of maintenance. These authors refer that the choice of the discount rate is mainly a political decision, and its value usually ranges between $4 \%$ and $6 \%$. In this study, the maintenance decisions and, consequently, the investment decisions are compared considering a discount rate of $0 \%$ and $5 \%$. The direct costs of each maintenance are presented in Table 7, based on the most recent values of each operation, found in the literature and specialized companies.

Figure 11 depicts the mean cumulative cost for the three maintenance strategies and Table 8 presents a comparison between the cumulative costs and the estimated service life of ceramic claddings, taking into account the three maintenance strategies proposed. As expected, for a discount rate of $5 \%$ (Figure 11(a)), the mean cumulative cost of maintenance strategy 1 (considering only major intervention) is lower than the cost of maintenance strategies 2 and 3.
However, for a $0 \%$ discount rate (Figure 11(b)), maintenance strategy 2 is the one with the lowest cumulative cost over the claddings' lifetime. Strategy 1, only considering a major intervention, is more expensive after the cladding's lifetime, but this is only noticeable after year 60 . Therefore, for a $0 \%$ discount rate, the inclusion of a minor intervention has clear advantages, since it improves the cladding's degradation condition and, consequently, its service life, and considerably delays the execution of a major intervention. This conclusion can also be observed in Figure 9, where in $94.69 \%$ of the 50,000 iterations run in the Monte Carlo simulation, no major interventions were applied. Moreover, the execution of two minor interventions is cheaper than one major intervention, which also allows reducing the long-term costs.

In an overall analysis, the following main conclusions can be drawn:

- Maintenance strategy 1 presents the lowest cumulative cost over the claddings' lifetime, for a discount rate of $5 \%$. In this strategy, only a corrective measure is adopted, which does not allow improving the claddings' condition over time, as well as their expected service life.

- Maintenance strategy 3 presents the worst overall results, since it leads to the highest cumulative costs over the claddings' lifetime, and the adoption of cleaning actions increases the estimated service life of ceramic claddings, but less than maintenance strategy 2 .

- Maintenance strategy 2 seems the most rational and adequate solution, according to the model's assumptions, since this strategy allows significantly increasing the estimated service life of ceramic claddings, and the cumulative costs over the claddings' lifetime are extremely competitive when compared with those of maintenance strategy 1.

\section{Conclusions}

In this study, a maintenance model, based on the Petri net formalism, is proposed to analyse the consequences of alternative maintenance strategies to control the deterioration levels of ceramic claddings in Portugal. The use of Petri nets to model the deterioration and maintenance of components is a research field in development. However, this modelling technique has shown several advantages when compared with other techniques, like Markov chains. The graphical representation of the model and its results can be used to describe the problem in an intuitive manner. Petri nets models are very flexible, allowing incorporating many rules 
in the model to accurately simulate complex situations and keeping the model's size within manageable limits. Furthermore, this modelling technique shows a good capability to asses and predict the life-cycle performance of building façades.

To evaluate the performance of ceramic claddings, without and with maintenance actions, three maintenance strategies were considered: (i) only major intervention; (ii) a combination of minor and major interventions; and (iii) a combination of cleaning operations, minor and major interventions. A Weibull distribution was chosen as the appropriate distribution to sample the transition times in the deterioration process. Furthermore, a triangular distribution was chosen to describe the inspection times of the façades. The choice of both distributions was performed based on the literature and on previous studies by the authors.

The major and minor interventions are modelled as condition-based corrective maintenance. All actions are performed after an initial inspection to evaluate the claddings' degradation condition. The major intervention is applied when the ceramic cladding reaches higher deterioration levels and when the end of service life is reached, and the whole cladding is replaced. On the other hand, the minor intervention is applied when the claddings have an intermediate deterioration level. In minor interventions, a cleaning action is performed, as well as the replacement of the filling material in joints and ceramic tiles, and filling of the cracking observed. The cleaning action is considered a preventive maintenance and is time-based, being applied every 10 years.

The complete Petri net maintenance model is divided into seven modules, with distinct functions: (i) deterioration process; (ii) inspection process; (iii) maintenance process; (iv) preventive maintenance; (v) corrective maintenance; (vi) periodicity of the preventive maintenance; and (vii) renewal process. The maintenance model is solved using a Monte Carlo simulation. The model allows obtaining some parameters related with the ceramic claddings' performance, such as: future condition profiles of the effects of the different maintenance strategies; number of interventions performed in the ceramic cladding over the simulated lifetime; distribution of times of application of the first intervention; and, cumulative cost profile of the different maintenance strategies, considering an annual discount rate.

The results reveal that the defined maintenance strategies have a significant impact on the mean condition level, when compared with the condition profile without maintenance. Maintenance strategy 1 represents the one most commonly implemented by owners. The future condition profiles obtained reveal that more regular interventions in the cladding, through the application of minor intervention and cleaning operations, allows improving the claddings' condition level. For strategy 1, a service life of 55.3 (only $0.4 \%$ of the claddings are not replaced in the time horizon) years was obtained, and an average of 1.40 major interventions are performed during a time horizon of 100 years.

The implementation of minor and major interventions allows increasing the estimated service life of ceramic claddings, since the probability of the claddings not being replaced increases from $0.4 \%$ to $94.69 \%$, where the first minor intervention is applied approximately after 33 years (only $0.01 \%$ of the claddings are not repaired in the time horizon). The combination of cleaning, minor and major interventions allows increasing the estimated service life, since the probability of the claddings not being replaced increases from $94.69 \%$ to $99.37 \%$. Furthermore, the results obtained revealed that until year 14.9 ceramic claddings only need to be monitored (only $0.002 \%$ of the claddings are not clean in the time horizon).

Regarding the cumulative cost profiles, maintenance strategy 1 has the lowest cumulative cost over the claddings' lifetime, for a discount rate of $5 \%$, but it does not promote the increase of the claddings' service life. For a discount rate of $0 \%$, maintenance strategy 2 has the lowest cumulative costs after the period under analysis. In this sense, this strategy seems the most appropriate, considering the proposed model, since it allows increasing the cladding's performance while reducing the maintenance costs over the claddings' lifetime.

\section{Acknowledgements}

The authors gratefully acknowledge the support of the CERIS Research Institute, IST, University of Lisbon and the FCT (Foundation for Science and Technology) through the program SFRH/BD/88195/2012, and through the projects SLPforBMS (PTDC/ECM-COM/5772/2014) and Best Maintenance-Lower Risks (PTDC/ECI-CON/29286/2017).

\section{Disclosure statement}

No potential conflict of interest was reported by the authors.

\section{ORCID}

Luís Canhoto Neves (D) http://orcid.org/0000-0001-5034-8417 Ana Silva (D) http://orcid.org/0000-0001-6715-474X

Jorge de Brito (D) http://orcid.org/0000-0001-6766-2736

\section{References}

Al-Ahmari, A. (2016). Optimal robotic cell scheduling with controllers using mathematically based timed Petri nets. Information Sciences, 329, 638-648. doi:10.1016/j.ins.2015.09.053

Andrews, J. (2013). A modelling approach to railway track asset management. Proceeding of the Institution of Mechanical Engineers, Part F: Journal of Rail and Rapid Transit, 227(1), 56-73. doi:10.1177/ 0954409712452235

Balaras, A., Droutsa, K., Dascalaki, E., \& Kontoyiannidis, S. (2005). Deterioration of European apartment buildings. Energy and Buildings, 37(5), 515-527. doi:10.1016/j.enbuild.2004.09.010

Baskocagil, C., \& Kurtulan, S. (2011). Generalized state equation for Petri nets. WSEAS Transactions on Systems, 10(9), 295-305.

Bérenguer, C., Grall, A., Dieulle, L., \& Roussignol, M. (2003). Maintenance policy for a continuously monitored deteriorating system. Probability in the Engineering and Informational Sciences, 17(2), 235-250. doi:10.1017/S0269964803172063

Bordalo, R., de Brito, J., Gaspar, P., \& Silva, A. (2011). Service life prediction modelling of adhesive ceramic tiling systems. Building Research \& Information, 39(1), 66-78. doi:10.1080/09613218.2010. 532197 
Bowden, F. D. J. (2000). A brief survey and synthesis of the roles of time in Petri nets. Mathematical and Computer Modelling, 31(10-12), 55-68. doi:10.1016/S0895-7177(00)00072-8

Brandt, E., \& Rasmussen, M. (2002). Assessment of building conditions. Energy and Buildings, 34(2), 121-125. doi:10.1016/S03787788(01)00102-5

CEN. (2012). Ceramic tiles-Definitions, classification, characteristics, evaluation of conformity and marking, EN 14411:2012. Brussels, Belgium: European Committee for Standardization.

Chen, Y., Li, Z., \& Barkaoui, K. (2014). Maximally permissive livenessenforcing supervisor with lowest implementation cost for flexible manufacturing systems. Information Sciences, 256, 74-90. doi:10. 1016/j.ins.2013.07.021

Cheng, F., Li, H., Wang, Y. W., Skitmore, M., \& Forsythe, P. (2013). Modeling resource management in the building design process by information constraint Petri nets. Automation in Construction, 29, 92-99. doi:10.1016/j.autcon.2012.08.005

CYPE $^{\circledR}$ (2016). CYPE Price generator. Retrieved from http://www.geradordeprecos.info/

David, R., \& Alla, H. (2010). Discrete, continuous, and hybrid Petri nets. Berlin: Springer Science \& Business Media.

Dieulle, L., Bérenguer, C., Grall, A., \& Roussignol, M. (2003). Sequential condition-based maintenance scheduling for a deteriorating system. European Journal of Operational Research, 150(2), 451-461. doi:10.1016/S0377-2217(02)00593-3

Dugan, J. B., Trivedi, K. S., Geist, R. M., \& Nicola, V. F. (1984). Extended stochastic Petri nets: applications and analysis. Technical report, Duke University, Durham, NC.

Eisenberger, D., \& Fink, O. (2017). Assessment of maintenance strategies for railway vehicles using Petri-nets. Transportation Research Procedia, 27, 205-214. doi:10.1016/j.trpro.2017.12.012

Ferreira, C., Neves, L. C., Silva, A., \& de Brito, J. (2018). Stochastic Petri net-based modelling of the durability of renderings. Automation in Construction, 87, 96-105. doi:10.1016/j.autcon.2017. 12.007

Ferreira, C., Neves, L. C., Silva, A., \& de Brito, J. (2019). Stochastic Petri-net models to predict the degradation of ceramic claddings. Building Research \& Information, 47(6), 697-715. doi:10.1080/ 09613218.2018.1501873

Flores-Colen, I., \& de Brito, J. (2010). A systematic approach for maintenance budgeting of buildings façades based on predictive and preventive strategies. Construction and Building Materials, 24(9), 1718-1729. doi:10.1016/j.conbuildmat.2010.02.017

Flores-Colen, I., de Brito, J., \& Freitas, V. (2009). Discussion of criteria for prioritization of predictive maintenance of building façades: Survey of 30 experts. Journal of Performance of Constructed Facilities, 24(4), 337-344. doi:10.1061/(ASCE)CF.1943-5509.0000104

Flourentzou, F., Brandt, E., \& Wetzel, C. (2000). MEDIC - a method for predicting residual service life and refurbishment investment budgets. Energy and Buildings, 31(2), 167-170. doi:10.1016/S03787788(99)00031-6

Forster, A. M., \& Kayan, B. (2009). Maintenance for historic buildings: A current perspective. Structural Survey, 27(3), 210-229. doi:10. 1108/02630800910971347

Frangopol, D. M., Kallen, M. J., \& van Noortwijk, J. M. (2004). Probabilistic models for lifecycle performance of deteriorating structures: review and future directions. Progress in Structural Engineering and Materials, 6(4), 197-212. doi:10.1002/pse.180

Frangopol, D. M., \& Liu, M. (2007). Maintenance and management of civil infrastructure based on condition, safety, optimization, and life-cycle cost. Structure and Infrastructure Engineering, 3(1), 29-41. doi:10.1080/15732470500253164

Gaspar, P., Brito, J. de (2011). Limit states and service life of cement renders on façades, Journal of Materials in Civil Engineering, 23(10), 1393-1404.

Kilsby, P., Remenyte-Prescott, R., \& Andrews, J. (2019). A Petri Netbased life cycle cost analysis approach. Proceedings of the Institution of Mechanical Engineers, Part F: Journal of Rail and Rapid Transit, 233(1), 90-102. doi:10.1177/0954409718780106
Kirkham, R. J., \& Boussabaine, H. (2005). Forecasting the residual service life of NHS hospital buildings: a stochastic approach. Construction Management and Economics, 53(1-2), 1-17. doi:10. 1080/0144619042000326729

Le, B., \& Andrews, J. (2016a). Petri net modelling of bridge asset management using maintenance-related state conditions. Structure and Infrastructure Engineering, 12(6), 730-751.

Le, B., \& Andrews, J. (2016b). Modelling wind turbine degradation and maintenance. Wind Energy, 19(4), 571-591. doi:10.1002/we.1851

Lei, Y., Liu, J., Ni, J., \& Lee, J. (2010). Production line simulation using STPN for maintenance scheduling. Journal of Intelligent Manufacturing, 21(2), 213-221. doi:10.1007/s10845-008-0194-1

Leigh, J. M., \& Dunnett, S. J. (2016). Use of Petri nets to model the maintenance of wind turbines. Quality and Reliability Engineering International, 32(1), 167-180. doi:10.1002/qre.1737

Li, H. (1998). Petri net as a formalism to assist process improvement in the construction industry. Automation in Construction, 7(4), 349-356. doi:10.1016/S0926-5805(98)00051-X

Liao, H., Elsayed, E. A., \& Chan, L.-Y. (2006). Maintenance of continuously monitored degrading systems. Computing, artificial intelligence and information management. European Journal of Operational Research, 175(2), 821-835. doi:10.1016/j.ejor.2005.05.017

Lowry, G. (2002). Modelling user acceptance of building management systems. Automation in Construction, 11(6), 695-705. doi:10.1016/ S0926-5805(02)00010-9

Madureira, S., Flores-Colen, I., de Brito, J., \& Pereira, C. (2017). Maintenance planning of facades in current buildings. Construction and Building Materials, 147, 790-802. doi:10.1016/j.conbuildmat. 2017.04.195

Marsan, M. A., \& Chiola, G. (1986). On Petri nets with deterministic and exponentially distributed firing times. In Proceedings of the European Workshop on Applications and Theory in Petri Nets. Springer, Berlin, Heidelberg.

Marsan, M. A., Conte, G., \& Balbo, G. (1984). A class of generalized stochastic Petri nets for the performance evaluation of multiprocessor systems. ACM Transactions on Computer Systems (TOCS), 2(2), 93-122. doi:10.1145/190.191

Molinero, C., \& Nunez, M. (2011). Planning of work schedules through the use of a hierarchical multi-agent system. Automation in Construction, 20(8), 1227-1241. doi:10.1016/j.autcon.2011.05.006

Murata, T. (1989). Petri nets: Properties, analysis and applications. Proceedings of the IEEE, 77(4), 541-580. doi:10.1109/5.24143

Neves, L. C., \& Frangopol, D. M. (2005). Condition, safety and cost profiles for deteriorating structures with emphasis on bridges. Reliability Engineering \& System Safety, 89(2), 185-198. doi:10.1016/ j.ress.2004.08.018

Peterson, J. L. (1977). Petri nets. Acm Computing Surveys, 9(3), 223-252. doi:10.1145/356698.356702

Petri, C. A. (1962). Kommunikation mit Automaten. Bonn: Institut für Instrumentelle Mathematik, Schriften des IIM Nr. 3 (Also, English translation, Communication with Automata. New York: Griffiss Air Force Base. Technical report RADC-TR-65-377, volume 1, supplement 1, 1966).

Plšková, I., Chobola, Z., \& Matysik, M. (2011). Assessment of ceramic tile frost resistance by means of the frequency inspection method. Ceramics-Silikáty, 55(2), 176-182.

Raposo, S., de Brito, J., \& Fonseca, M. (2013). Planned preventive maintenance activities: Analysis of guidance documents. In Durability of Building Materials and Components (pp. 35-60). Berlin, Heidelberg: Springer.

Rinke, N., von Gösseln, I., Kochkine, V., Schweitzer, J., Berkhahn, V., Berner, F., Kutterer, H., Neumann, I., \& Schwieger, V. (2017). Simulating quality assurance and efficiency analysis between construction management and engineering geodesy. Automation in Construction, 76, 24-35. doi:10.1016/j.autcon.2017.01.009

Schneeweiss, W. G. (2004). Petri net picture book (an elementary introduction to the best pictorial description of temporal changes). Germany: LiLoLe-Verlag GmbH.

Simeu-Abazi, Z., \& Sassine, C. (1999). Maintenance integration in manufacturing systems by using stochastic Petri nets. International 
Journal of Production Research, 37(17), 3927-3940. doi:10.1080/ 002075499189844

Shohet, I., Puterman, M., \& Gilboa, E. (2002). Deterioration patterns of building cladding components for maintenance management. Construction Management and Economics, 20(4), 305-314. doi:10. 1080/01446190210125563

Shohet, I., \& Paciuk, M. (2004). Service life prediction of exterior cladding components under standard conditions. Construction Management and Economics, 22(10), 1081-1090. doi:10.1080/0144619042000213274

Shohet, I. (2006). Key performance indicators for strategic healthcare facilities maintenance. Journal of Construction Engineering and Management, 132(4), 345-352. doi:10.1061/(ASCE)0733-9364(2006)132:4(345)

Silva, A., Gaspar, P. L., de Brito, J., \& Neves, L. C. (2016). Probabilistic analysis of degradation of façade claddings using Markov chain models. Materials and Structures, 49(7), 2871-2892. doi:10.1617/ s11527-015-0692-5

Silva, A., de Brito, J., \& Gaspar, P. (2016). Methodologies for service life prediction of buildings: With a focus on façade claddings. Switzerland: Springer International Publishing.

Silvestre, J. D., \& de Brito, J. (2011). Ceramic tiling in building façades: Inspection and pathological characterization using an expert system. Construction and Building Materials, 25(4), 1560-1571. doi:10.1016/ j.conbuildmat.2010.09.039

Sherwin, D. (2000). A review of overall models for maintenance management. Journal of Quality in Maintenance Engineering, 6(3), 138-164. doi:10.1108/13552510010341171

Tang, F., Guo, M., Dong, M., Li, M., \& Guan, H. (2008). Towards context-aware workflow management for ubiquitous computing. In 2008 International Conference on Embedded Software and Systems (pp. 221-228). IEEE.
Thai-Ker, L., \& Chung-Wan, W. (2006). Challenges of external wall tiling in Singapore. In Qualicer 2006: IX World Congress on Ceramic Tile Quality, Castellón, Spain.

Uzam, M., Gelen, G., \& Saleh, T. L. (2016). Think-globally-act-locally approach with weighted arcs to the synthesis of a liveness-enforcing supervisor for generalized Petri nets modeling FMSs. Information Sciences, 363, 235-260. doi:10.1016/j.ins.2015.09.010

van der Aalst, W. M. (2002). Making work flow: On the application of petri nets to business process management. In International conference on application and theory of Petri nets (pp. 1-22). Springer, Berlin, Heidelberg.

van Noortwijk, J. M., \& Frangopol, D. M. (2004). Two probabilistic life-cycle maintenance models for deteriorating civil infrastructures. Probabilistic Engineering Mechanics, 19(4), 345-359. doi:10.1016/j. probengmech.2004.03.002

Yang, S. K., \& Liu, T. S. (1998). A Petri net approach to early failure detection and isolation for preventive maintenance. Quality and Reliability Engineering International, 14(5), 319-330. doi:10.1002/ (SICI)1099-1638(199809/10)14:5<319::AID-QRE171>3.0.CO;2-6

Yianni, P., Rama, D., Neves, L., Andrews, J., \& Castlo, D. (2017). A Petri-net-based modelling approach to railway bridge asset management. Structure and Infrastructure Engineering, 13(2), 287-297. doi: 10.1080/15732479.2016.1157826

Zhang, D., Hu, H., \& Roberts, C. (2017). Rail maintenance analysis using Petri nets. Structure and Infrastructure Engineering, 13(6), 783-793. doi:10.1080/15732479.2016.1190767

Zille, V., Bérenguer, C., Grall, A., \& Despujols, A. (2011). Modelling multicomponent systems to quantify reliability centred maintenance strategies. Proceedings of the Institution of Mechanical Engineers, Part O: Journal of Risk and Reliability, 225(2), 141-160. doi:10.1177/ 1748006X11402269 